\title{
SCANS (Shipping Cask ANalysis System) A Microcomputer Based Analysis System for Shipping Cask Design Review
}

\section{Volume 4--Theory Manual Thermal Analysis}

Manuscript Completed: January 1989

Date Published: February 1989

Prepared by

G. L. Johnson and A. B. Shapiro

Lawrence Livermore National Laboratory

7000 East Avenue

Livermore, CA 94550

Prepared for

Division of Engineering

Office of Nuclear Regulatory Research

U.S. Nuclear Regulatory Connmission

Washington, DC 20555

NRC FIN A0374

This document is

PUBLICL $P$ PEASABLE

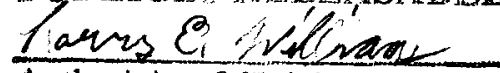

Authorizing Official

Date: 121212005

\section{DISCLAIMER}

This report was prepared as an account of work sponsored by an agency of the United States Government. Neither the United States Government nor any agency thereof, nor any of their employees, makes any warranty, express or implied, or assumes any legal liability or responsibility for the accuracy, completeness, or usefulness of any information, apparatus, product, or process disclosed, or represents that its use would not infringe privately owned rights. Reference herein to any specific commercial product, process, or service by trade name, trademark, manufacturer, or otherwise does not necessarily constitute or imply its endorsement, recommendation, or favoring by the United States Government or any agency thereof. The views and opinions of authors expressed herein do not necessarily state or reflect those of the - Uníted States Government or any agency thereof.

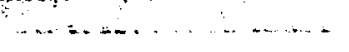




\section{DISCLAIMER}

This report was prepared as an account of work sponsored by an agency of the United States Government. Neither the United States Government nor any agency Thereof, nor any of their employees, makes any warranty, express or implied, or assumes any legal liability or responsibility for the accuracy, completeness, or usefulness of any information, apparatus, product, or process disclosed, or represents that its use would not infringe privately owned rights. Reference herein to any specific commercial product, process, or service by trade name, trademark, manufacturer, or otherwise does not necessarily constitute or imply its endorsement, recommendation, or favoring by the United States Government or any agency thereof. The views and opinions of authors expressed herein do not necessarily state or reflect those of the United States Government or any agency thereof. 


\section{DISCLAIMER}

Portions of this document may be illegible in electronic image products. Images are produced from the best available original document. 


\begin{abstract}
TOPAZ is the two-dimensional, implicit, finite-element computer code included in the SCANS cask analysis system for heat conduction calculations. TOPAZ, a code developed on LLNL mainframes, has been implemented on IBM PC computers. This report provides documentation of TOPAZ controls and variables and a description of the numerical algorithms used. Sample problems with analytical solutions are presented.
\end{abstract}


Page

Abstract

List of Figures vii

List of Tables ix

Nomenclature . $x i$

Acknowledgments xii i

Executive Summary xv

1.0 Introduction

2.0 General Theory

2.1 Conduction of Heat in an Orthotropic Solid ................................... 2

2.2 Finite Element Formulation............................................... 3

2.3 Time Integration Scheme.................................................... 8

2.4 Thermal Contact Resistance Across an Interface

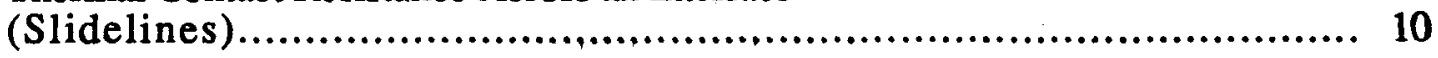

2.5 Enclosure Radiation ....................................................... 14

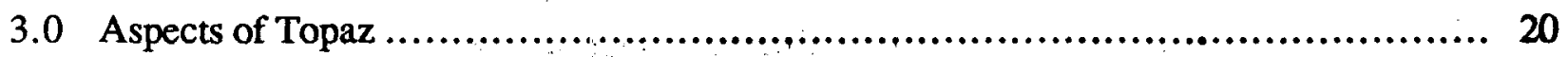

3.1 Bandwidth Minimization...................................................... 20

3.2 Boundary Conditions........................................................ 20

3.3 Bulk Fluid .............................................................. 23

3.4 Element Types.................................................................. 24

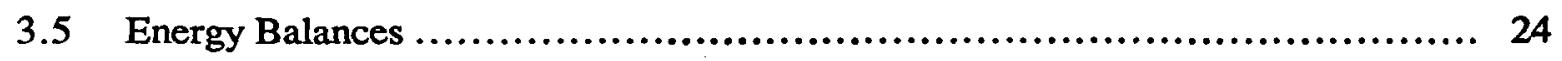

3.6 Function Definitions...................................................... 24

3.7 Heat Generation.......................................................... 25

3.8 Initial Conditions....................................................... 25

3.9 Internal Boundary Elements .............................................. 26

3.10 Material Properties......................................................... 26

3.11 Mesh Generation ......................................................... 27

3.12 Nonlinear Analysis .......................................................... 27

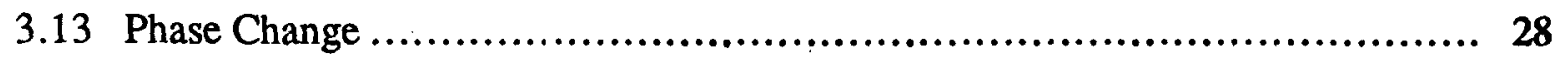

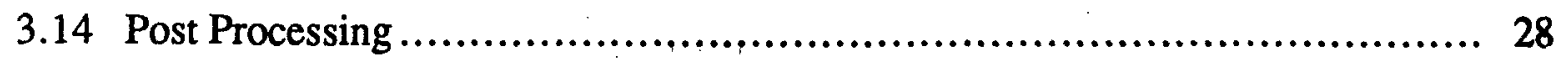

3.15 Radiation in Enclosures .................................................. 28 
3.16 Slidelines - Thermal Contact Resistance Across

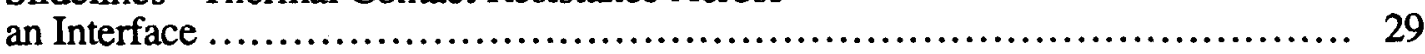

3.17 Steady-State Analysis ....................................................... 30

3.18 Thermal Stress Analysis ..................................................... 30

3.19 Transient Analysis ........................................................... 30

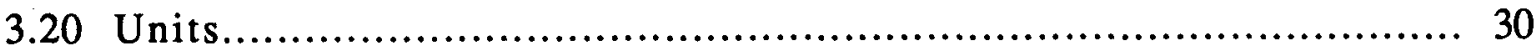

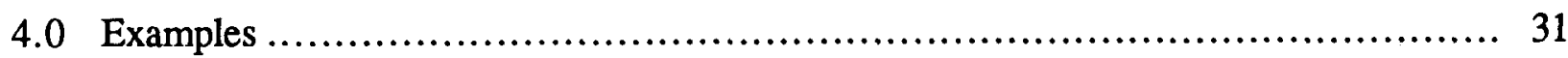

4.1 Introduction................................................................. 31

4.2 Example 1 - Finite Cylinder with 2

4.3 Example 2 - Slab with Nonlinear

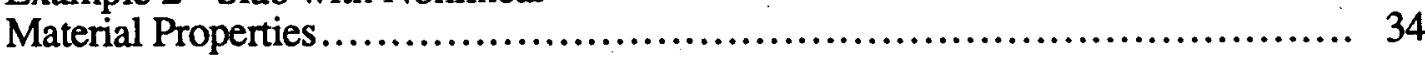

4.4 Example 3 - Cylinder with Temperature + Convection Boundary Conditions

4.5 Example 4-One-Dimensional Cylinder with Heat-Generating Core ............................................... 39

4.6 Example 5 - Finite Rod with Band Heating............................................ 42

4.7 Example 6 - Finite Cylinder with Strip Heating and Cooling

4.8 Example 7 - Finite Hollow Cylinder with Inside Band Heating.

4.9 Example 8 --Regulation Case-Normal Hot Day with Maximum

Decay Heat/Solar Heat ....................................................... 48

4.10 Example 9 - Regulation Case-Cold Soak with Maximum Decay Heat/No Solar Heat.

5.0 References 


\section{LIST OF FIGURES}

Figure 2-1 Two-dimensional heat condúction with heat flow at external

Page

boundary ..................................................................... 2

Figure 2-2 Solid body overlayed with a quadrilateral grid................................. 6

Figure 2-3 Bilinear quadrilateral element domain..................................... 6

Figure 2-4 Added elements for contact resistance or slideline........................... II

Figure 2-5 Typical triangular element at gap or slideline................................... 11

Figure 2-6 Relationship between local and global coordinates.......................... 14

Figure 2-7 Boundary conductions at wall surface ................................... 15

Figure 3-1 Direction of outward normal vector with respect to nodes .................... 20

Figure 3-2 Setting boundary linearly varying flux boundary conditions

on surface segment........................................................ 21

Figure 3-3 Heat flow between bulk node (B) and adjoining surface (S).................. 23

Figure 3-4 Degeneration from four node into three node element ...................... 24

Figure 3-5 Piecewise linear curve for interpolation.................................... 25

Figure 3-6 Thermal coupling between two surfaces...................................... 26

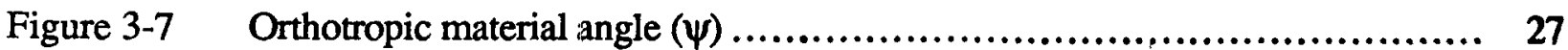

Figure 3-8 Relationship of boundaries for an enclosure ............................... 28

Figure 3-9 Relationship between slave and master surfaces................................ 29

Figure 4-1 Solid finite cylinder with two surface temperatures ......................... 31

Figure 4-2 Analytical and numerical results for a steady-state heat flow

in a finite cylinder with two surface temperatures ........................... 33

Figure 4-3 Heat conduction in homogeneous isotropic slab.............................. 34

Figure 4-4 Finite solid cylinder with convection....................................... 37

Figure 4-5 Analytical and numerical results of temperature plus convection boundary conditions in a cylinder .......................................... 38

Figure 4-6 SNL Model 1 geometry and LLNL finite element mesh....................... 39

Figure 4-7 Analytical and numerical results for one dimensional cylinder with internal heating....................................................... 41

Figure 4-8 Finite rod with heating band ......................................... 42

Figure 4-9 Analytical and numerical results for steady-state heat flow in a finite rod with band heating

Figure 4-10 Finite cylinder with strip heating and cooling............................ 44

Figure 4-11 Analytical and numerical results for steady-state heat flow in a finite cylinder with strip heating and cooling 


\section{LIST OF FIGURES (con't)}

Figure 4-12 Finite hollow cylinder with inside band heating $\ldots \ldots \ldots \ldots \ldots \ldots \ldots \ldots \ldots \ldots \ldots . \ldots 6$

Figure 4-13 Analytical and numerical results for steady-state heat

flow in a finite hollow cylinder with inside band heating

Figure 4-14 Geometry and finite element mesh for regulation case. Normal hot with maximum heat.

Figure 4-15 Comparison between the CRAY version of TOPAZ and the PC version of TOPAZ for Example 8

Figure 4-16 Comparison between the CRAY version of TOPAZ and the $\mathrm{PC}$ version of TOPAZ for Example 9. 


\section{LIST OF TABLES}

Table 4-1 : Input data for Example 1..

Table 4-1 ' Input data for Example 1............................................ 32

Table 4-2 Input data for Exarnple 2................................................. 35

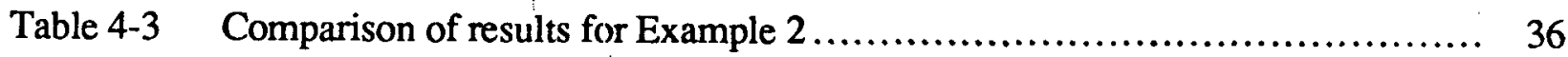

Table 4-4 Input data for Exarnple 3.................................................. 37

Table 4-5 Input data for Exarnple 4.................................................... 40

Table 4-6 Input data for Example 5.................................................. 42

Table 4-7 Input data for Example 6................................................. 44

Table 4-8 Input data for Example 7................................................ 46

Table 4-9 Stainless steel specific heat capacity and thermal conductivity ................ 49

Table 4-10 Lead specific heat capacity and thermal conductivity.......................... 49

Table 4-11 Polyurethane form specific heat capacity and thermal conductivity............... 50 


\section{NOMENCLATURE}

[Units: $M=$ mass, $\mathrm{L}=$ length, $\mathrm{E}=$ energy, $\theta=$ temperature, $\mathrm{T}=$ time]

\begin{tabular}{|c|c|c|}
\hline$\rho$ & $=$ & density $\left[M / L^{3}\right]$ \\
\hline c & $=$ & specific heat capacity $[\mathrm{E} / \mathrm{M} \theta]$ \\
\hline$\theta, \mathrm{T}$ & $=$ & temperature $[\theta]$ \\
\hline $\mathrm{t}$ & $=$ & time $[\mathrm{T}]$ \\
\hline$x($ or $r)$ & $=$ & coordinate in $\mathrm{x}$ direction (or radial direction) $[\mathrm{L}]$ \\
\hline$y($ or $z)$ & $=$ & coordinate in y direction (or axial direction) $[\mathrm{L}]$ \\
\hline $\mathrm{k}_{\mathrm{x}}\left(\right.$ or $\left.\mathrm{k}_{\mathrm{y}}\right)$ & $=$ & thermal conductivity in $x$ direction (or $y$ direction) $[\mathrm{E} / \mathrm{LT} \theta]$ \\
\hline $\mathrm{n}_{\mathrm{x}}\left(\right.$ or $\left.\mathrm{n}_{\mathrm{y}}\right)$ & $=$ & fraction of bounding surface unit normal in $\mathrm{x}$ direction (or $\mathrm{y}$ direction) \\
\hline$q_{g}$ & $=$ & volumetric heat generation $\left[\mathrm{E} / \mathrm{L}^{3} \mathrm{~T}\right]$ \\
\hline$\beta$ & $=$ & $\begin{array}{l}\text { coefficient relating environment-imposed surface heat loads to environment } \\
\text { temperature }\left[\mathrm{E} / \mathrm{L}^{2} \mathrm{~T} \theta\right]\end{array}$ \\
\hline$\gamma$ & $=$ & $\begin{array}{l}\text { parameter defining environment-imposed surface heat loads which are not } \\
\text { driven by the environment temperature }\left[E / L^{2} T\right]\end{array}$ \\
\hline $\mathrm{q}_{\mathrm{f}}$ & $=$ & environment-imposed surface heat flux $\left[\mathrm{E} / \mathrm{L}^{2} \mathrm{~T}\right]$ \\
\hline$\dot{\mathrm{q}}$ & $=$ & local net heat flux $\left[\mathrm{E} / \mathrm{L}^{2} \mathrm{~T}\right]$ \\
\hline$\omega$ & $=$ & weighting function for integration \\
\hline $\mathrm{h}_{\mathrm{c}}$ & $=$ & convective heat transfer coefficient $\left[\mathrm{E} / \mathrm{L}^{2} \mathrm{~T} \theta\right]$ \\
\hline$\theta_{\infty}, T_{\infty}$ & $=$ & temperature of environment \\
\hline $\mathrm{T}_{\text {surf }}$ & $=$ & boundary surface ternperature $[\theta]$ \\
\hline$\sigma$ & $=$ & Stefan-Boltzman coefficient for thermal radiation heat transfer $\left[\mathrm{E} / \mathrm{L}^{2} \mathrm{~T} \theta^{4}\right]$ \\
\hline $\mathcal{F}$ & $=$ & exchange factor for thermal radiation \\
\hline$\theta_{\mathrm{i}}, \mathrm{T}_{\infty}$ & $=$ & temperature at each node \\
\hline $\mathbf{N}_{\mathbf{i}}$ & $=$ & Finite element shape factor \\
\hline$\alpha$ & $=$ & fraction of time step at which to evaluate solution matrices (see pages 9 - 11) \\
\hline$\psi$ & $=$ & angle of slideline surfaces to global coordinates \\
\hline $\mathrm{H}_{\mathbf{i}}$ & $=$ & radiant flux incident on a surface $i$ (irradiance) $\left[\mathrm{E} / \mathrm{L}^{2} \mathrm{~T}\right]$ \\
\hline $\mathbf{B}_{\mathbf{j}}$ & $=$ & radiation leaving surface $\mathrm{j}$ (radiosity) $\left[\mathrm{E} / \mathrm{L}^{2} \mathrm{~T}\right]$ \\
\hline$\varepsilon_{\mathrm{j}}$ & $=$ & emissivity of radiating surface $j$ \\
\hline$\alpha_{i}$ & $=$ & absorptance of emitting surface $i$ \\
\hline$\rho_{\mathbf{i}}$ & $=$ & reflectivity of surface $i=\left(1-\alpha_{i}\right)$ \\
\hline$A_{i}$ & $=$ & area of surface segment i $\left[\mathrm{L}^{2}\right]$ \\
\hline$F_{i j}$ & $=$ & geometric view factor between surface segments $i$ and $j$ \\
\hline $\operatorname{Pr}$ & $=$ & Prandtl Number = ratio of kinematic viscosity to thermal diffusivity \\
\hline
\end{tabular}




$\begin{array}{lll}\mathrm{Gr}_{\mathrm{L}} & =\quad \begin{array}{l}\text { Grashof Number }=\text { ratio of buoyancy forces to viscous forces in a free } \\ \text { convection flow }\end{array} \\ \mathrm{k}_{\mathrm{f}} & =\quad \begin{array}{l}\text { thermal conductivity of flowing medium in environment (evaluated at } \\ \mathrm{T}_{\mathrm{f}}=\left(\mathrm{T}_{\text {surf }}+\mathrm{T}_{\infty}\right) / 2[\mathrm{E} / \mathrm{TL} \theta]\end{array} \\ \mathrm{v}_{\mathrm{f}} & =\quad \begin{array}{l}\text { kinematic viscosity of flowing medium in environment } \\ \left(\text { evaluated at } \mathrm{T}_{\mathrm{f}}=\left(\mathrm{T}_{\text {surf }}+\mathrm{T}_{\infty}\right) / 2\left[\mathrm{~L}^{2} / \mathrm{T}\right]\right.\end{array} \\ \beta_{\mathrm{f}} & =\quad \begin{array}{l}\text { volume expansion coefficient of environment }[1 / \theta] \\ \mathrm{L}\end{array} \quad=\quad \begin{array}{l}\text { characteristic length of surface exposed to natural convection }[\mathrm{L}] \\ \mathrm{g}\end{array} \quad=\quad \text { acceleration due to gravity }\left[\mathrm{L} / \mathrm{T}^{2}\right]\end{array}$




\section{ACKNOWLEDGMENTS}

The authors would like to thank H. Graves and W. Campbell, technical monitors at the U.S. Nuclear Regulatory Commission for their support and technical direction in the development of the SCANS thermal and pressure stress modules and documentation. Many thanks to M. Kamelgarn for editing. 


\section{EXECUTIVE SUMMARY}

Lawrence Livermore National Laboratory has developed a microcomputer-based analysis system to assist the Nuclear Regulatory Commission in performing confirmatory analyses for licensing review of radioactive-material shipping cask designs.

This volume (Volume 4) is the Thermal Analysis Theory Manual. In this manual we describe the thermal analysis computer code TOPAZ which is incorporated into the Shipping Container Analysis System (SCANS). Benchmarking example problems are also presented. 


\section{SCANS (Shipping Cask ANalysis System) \\ Volume 4--Theory Manual \\ Thermal Analysis*}

\subsection{INTRODUCTION}

TOPAZ is the two-dimensional implicit finite element computer code for heat conduction analysis included in the Shipping Container ANalysis System (SCANS). This report documents the equations solved and gives a description of the numerical algorithms used. Sample problems with analytical solutions are presented. TOPAZ has been implemented on IBM PCs.

SCANS is a system of menus and programs used on PCs to complete thermal and impact analyses of type B shipping cask designs being reviewed for certification by the U.S. Nuclear Regulatory Commission. The thermal loads required by NRC regulations are built into SCANS. SCANS includes an input data editor, a finite element mesh generator, analytic codes to predict thermal and structural response, and codes to graphically display the meshes and the results from the analyzers.

TOPAZ can be used to solve for the steady-state or transient temperature field on two-dimensional planar or axisymmetric geometries. Material properties may be temperature-dependent and either isotropic or orthotropic. A variety of time- and temperature-dependent boundary conditions can be specified; these include temperature, flux, convection, and radiation. TOPAZ can solve problems of diffuse band radiation in an enclosure coupled with conduction in the material surrounding the enclosure. Additional features include analyses of thermal contact resistance across an interface, bulk fluids, phase change, and energy balances. 


\subsection{GENERAL THEORY}

\subsection{Conduction of Heat in an Orthotropic Solid}

The differential equation of conduction of heat in a two-dimensional solid is given by

$$
\rho c \frac{\partial \theta}{\partial t}=\frac{\partial}{\partial x} k_{x} \frac{\partial \theta}{\partial x}+\frac{\partial}{\partial y} k_{y} \frac{\partial \theta}{\partial y}+q_{g} \text { in the volume } \Omega
$$

subject to the boundary condition

$$
k_{x} \frac{\partial \theta}{\partial x} n_{x}+k_{y} \frac{\partial \theta}{\partial y} n_{y}+\beta\left(\theta-\theta_{\infty}\right)=\gamma \text { on the boundary surfaces } \Gamma
$$

and with the initial condition

$$
\theta=\theta(x, y) \quad \text { at } t=t_{0} \text {. }
$$

Equations (1)-(3) represent the strong form of a boundary value problem to be solved for the temperature field within the solid as shown in Fig. 2-1.

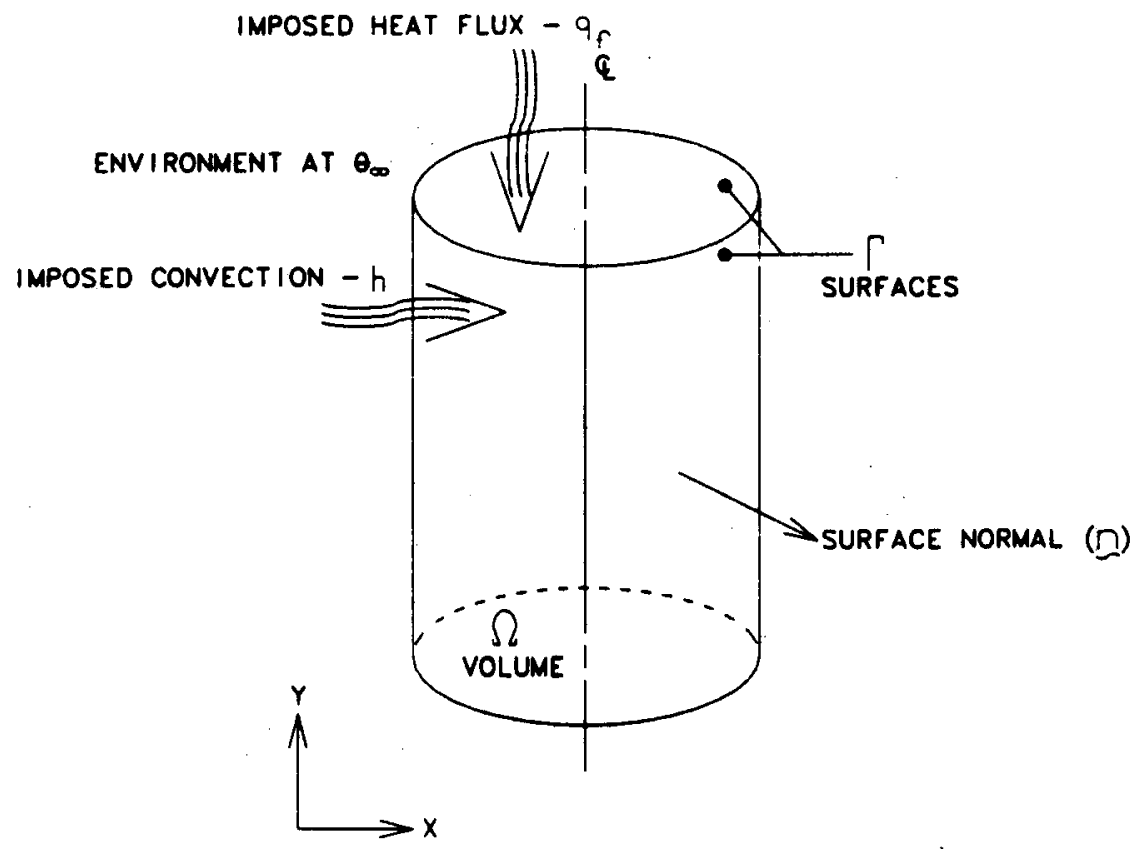

Figure 2-1 Two-dimensional heat conduction with heat flow at external boundary. 


\subsection{Finite Element Formulation}

A weak form of this boundary value problem is obtained by requiring each side of Eq. (1) to be satisfied in an average sense.

$$
\iint_{\Omega} \omega p c \frac{\partial \theta}{\partial t} d x d y=\iint_{\Omega} \omega\left[\frac{\partial}{\partial x} k_{x} \frac{\partial \theta}{\partial y}+\frac{\partial \theta}{\partial y} k_{y} \frac{\partial \theta}{\partial y}\right] d x d y+\iint_{\Omega} \omega q_{g} d x d y .
$$

The weighting function, $\omega$, is any function of $x$ and $y$ that is sufficiently well-behaved that the integrals make sense. Integrating the first term on the right side of Eq. (4) by parts results in a weak form of the boundary value problem (see Appendix 3 of [1]).

$$
\begin{array}{ll}
\text { time dependency } & \iint_{\Omega} \omega p c \frac{\partial \theta}{\partial t} d x d y= \\
\text { heat conduction } & -\iint_{\Omega}\left[\frac{\partial \omega}{\partial x} k_{x} \frac{\partial \theta}{\partial x}+\frac{\partial \omega}{\partial y} k_{y} \frac{\partial \theta}{\partial y}\right] d x d y \\
\text { natural boundary condition } \quad+\iint_{\Gamma} \omega\left[k_{x} \frac{\partial \theta}{\partial x} n_{x}+k_{y} \frac{\partial \theta}{\partial y} n_{y}\right] d \Gamma \\
\text { internal heat generation } \quad+\iint_{\Omega} \omega \mathrm{q}_{\mathrm{g}} \mathrm{dxdy} .
\end{array}
$$

Notice the appearance of the "natural" boundary condition term in Eq. (5) resulting from the integration by parts operation. Several forms of the boundary condition Eq. (2) will now be substituted for the natural boundary condition term. Equation (2) can be rewritten as

$$
k_{x} \frac{\partial \theta}{\partial x} n_{x}+k_{y} \frac{\partial \theta}{\partial y} n_{y}=\gamma-\beta\left(\theta-\theta_{\infty}\right)
$$

Heat flow in the TOPAZ computer code is positive in the direction of the surface-outward normal vector. A flux (or Neumann type) boundary condition on a surface segment can be represented by specifying

$$
\begin{aligned}
& \beta=0, \\
& \gamma=-q_{\mathrm{f}} .
\end{aligned}
$$$$
\text { (FLUX B.C.) }
$$ 
in Eq. (6). A convection (or Robin type) boundary condition can be represented by specifying

$$
\begin{aligned}
& \beta=h_{c}, \\
& \gamma=0 .
\end{aligned}
$$

(CONVECTION B.C.)

in Eq. (6). Equation (8) can also be used for a radiation boundary condition by utilizing a radiantheat transfer coefficient.

$$
h_{r}=\sigma F\left(\theta+\theta_{\infty}\right)\left(\theta^{2}+\theta_{\infty}^{2}\right) . \quad \text { (RADIATION B.C.) }
$$

The forced (or Dirichlet type) boundary condition in which the TEMPERATURE is specified on the boundary is imposed on the final system of equations by a penalty method.

For now, let a heat flux be applied on the boundary segment, $\Gamma_{\mathrm{f}}$, and heat transfer occur by convection on the boundary segment, $\Gamma_{C}$. Utilizing Eqs. (6) - (8), Eq. (5) becomes

$$
\begin{array}{ll}
\text { time dependency } & \iint_{\Omega} \omega \rho c \frac{\partial \theta}{\partial t} d x d y= \\
\text { heat conduction } & -\iint_{\Omega}\left[\frac{\partial \omega}{\partial x} k_{x} \frac{\partial \theta}{\partial x}+\frac{\partial \omega}{\partial y} k_{y} \frac{\partial \theta}{\partial y}\right] d x d y \\
\text { flux b.c. } & -\int_{\Gamma_{\mathrm{f}}} \omega \mathrm{q}_{\mathrm{f}} \mathrm{d} \Gamma_{\mathrm{f}} \\
& +\int_{\Gamma_{\mathrm{c}}} \omega \mathrm{h}_{\mathrm{c}} \theta_{\infty} \mathrm{d} \Gamma_{\mathrm{c}} \\
\text { convection b.c. }\left\{\begin{array}{l}
-\int_{\Gamma_{\mathrm{c}}} \omega \mathrm{h}_{\mathrm{c}} \theta \mathrm{d} \Gamma_{\mathrm{c}} \\
\end{array}\right. \\
\text { internal heat generation } \\
+\int_{\Omega} \omega \mathrm{q}_{\mathrm{g}} \mathrm{dxdy} .
\end{array}
$$

Galerkin's method consists of seeking an approximate solution to Eq. (10). This proceeds by assuming a trial (shape) function expansion for $\theta$,

$$
\theta=\sum_{i=1}^{n} N_{i} \theta_{i}=N \theta
$$


and taking as the weighting function

$$
\omega=N_{i} \text {. }
$$

Using the relations Eq. (11) in Eq. (10) results in

$$
\begin{aligned}
& {\left[\iint_{\Omega} N_{i} \rho c N d x d y\right]\left\{\frac{\partial \theta}{\partial t}\right\}=\left[-\iint_{\Omega} \nabla^{T} N_{i} K \nabla N d x d y\right]\{\theta\}} \\
& -\int_{\Gamma_{f}} N_{i} q_{f} d \Gamma_{f}+\int_{\Gamma_{c}} N_{i} h_{c} \theta_{c o} d \Gamma_{c}-\left[\int_{\Gamma_{c}} N_{i} h_{c} N d \Gamma_{c}\right]\{\theta\} \\
& +\iint_{\Omega} N_{i} q_{g} d x d y
\end{aligned}
$$

where

$$
(i=1,2, \ldots, n)
$$

or a set of discrete equations of the form

$$
[C]\{\dot{\theta}\}+[H]\{\theta\}=\{F\} \text {. }
$$

with

$$
\begin{aligned}
& {\left[C_{i j}\right]=\iint_{\Omega} N_{i} \rho c N_{j} d x d y} \\
& {\left[H_{i j}\right]=\iint_{\Omega} \nabla^{T} N_{i} K \nabla N_{j} d x d y+\int \Gamma_{c} N_{i} h_{c} N_{j} d \Gamma_{c}} \\
& \left\{F_{i}\right\}=\iint_{\Omega} N_{i} q_{g} d x d y-\int N_{r_{f}} N_{i} q_{f} d \Gamma_{f}+\int \Gamma_{c} N_{i} h_{c} \theta_{\infty} d \Gamma_{c}
\end{aligned}
$$

The finite element method provides a technique for spatial discretization of the body and construction of shape functions, $\mathrm{N}_{\mathrm{i}}$, for the numerical solution of Eq. (13). Let the domain, $\Omega$, be partitioned into a finite number of four node quadrilateral elements, $\Omega^{e}$, interconnected at their nodal points, Fig. 2-2.

Having constructed a finite element mesh for the problem, we proceed to construct a corresponding set of shape functions. In constructing the shape functions, we seek a change in coordinates which maps the given quadrilateral into a biunit square (Fig. 2-3). This standardizes the subsequent integration of Eq. (15). 


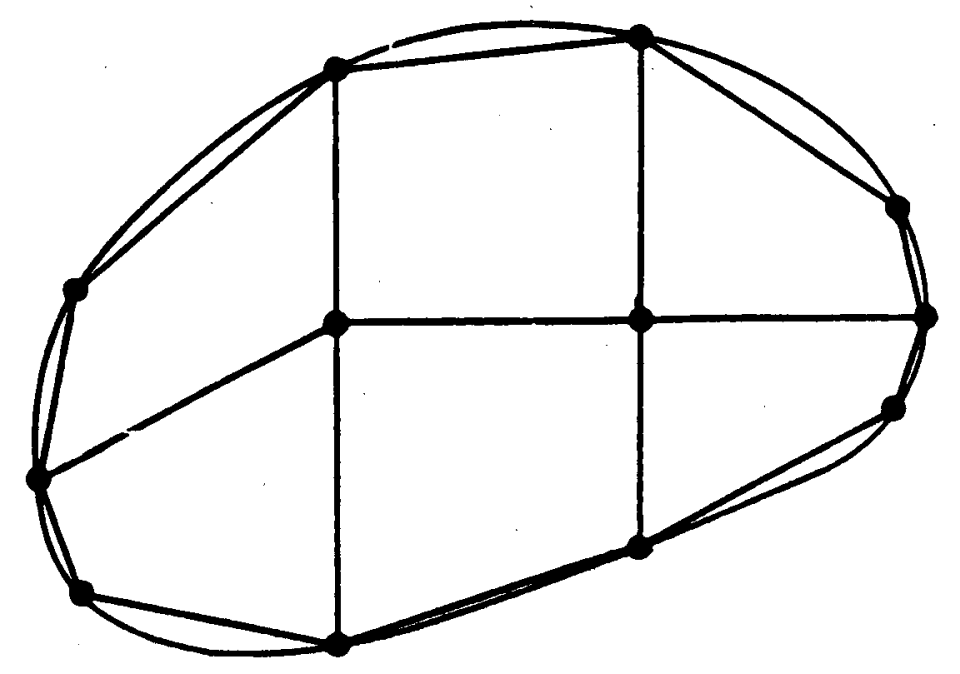

Figure 2-2 Solid body overlayed with a quadrilateral grid.
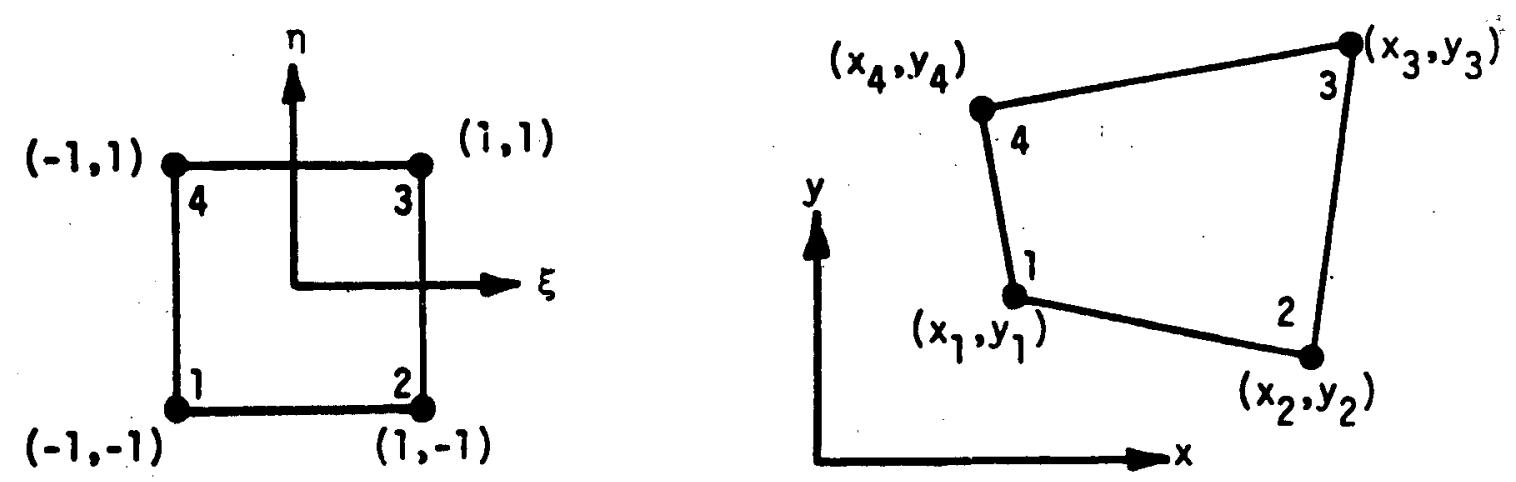

Figure 2-3 Bilinear quadrilateral element domain. 
We seek the temperature at the nodal points. This achieves the spatial discretization, and we now require that

$$
\begin{aligned}
& {[C]=\sum_{\mathbf{e}}\left[C_{i j}^{e}\right]=\sum_{e} \iint_{\Omega^{e}} N_{i} \rho c N_{j} d x d y} \\
& \begin{aligned}
{[H]=\sum_{e}\left[H_{i j}^{e}\right]=\sum_{e} \iint_{\Omega^{e}} \nabla^{T} N_{i} K \nabla N_{j} d x d y+\int_{\Gamma_{c}^{e}} N_{i} h_{c} N_{j} d \Gamma_{c} } \\
i=1,2,3,4 \\
j=1,2,3,4
\end{aligned} \\
& \begin{array}{ll}
e=1,2, \ldots, n \\
\{F\}=\sum_{e}\left[F_{i}^{e}\right]=\sum_{e} \iint_{\Omega^{e}} N_{i} q_{B} d x d y-\int_{\Gamma_{f}^{e}} N_{i} q_{f} d \Gamma_{f}+\int_{\Gamma_{c}^{e}} N_{i} h_{c} \theta_{\Omega} d \Gamma_{c}
\end{array}
\end{aligned}
$$

for substitution into Eq. (13).

$$
\begin{aligned}
& x(\varepsilon, \eta)=\sum_{i=1}^{4} N_{i}(\varepsilon, \eta) x_{i}^{e} \\
& y(\varepsilon, \eta)=\sum_{i=1}^{4} N_{i}(\varepsilon, \eta) y_{i}^{e}
\end{aligned}
$$

where the shape function $N_{i}(\varepsilon, \eta)$ for node i defined as

$$
N_{i}(\varepsilon, \eta)=\frac{1}{4}\left(1+\varepsilon_{i} \varepsilon\right)\left(1+\eta_{i} \eta\right)
$$

relates points in the biunit square $\left(\varepsilon, \eta\right.$ coordinate system) to coordinates of a point in $\Omega^{e}(x, y$ coordinate system), Fig. 2-3. We also require that the temperature be interpolated by these same shape functions (i.e., the isoparametric concept).

$$
\theta(\varepsilon, \eta)=\sum_{i=1}^{4} N_{i}(\varepsilon, \eta) \theta_{i}^{e}
$$

Equation (15) is now written as furictions of the new variables $\varepsilon$ and $\eta$ That is, the integrands are expressed in terms of $\varepsilon$ and $\eta$ and dxdy is replaced by ded $\eta$ times the absolute value of the Jacobian J. In general, 


$$
\iint_{\Omega} f(x, y) d x d y=\int_{-1}^{1} \int_{-1}^{1} f[x(\varepsilon, \eta), y(\varepsilon, \eta)] J d \varepsilon d \eta
$$

where

$$
J=\left[\begin{array}{l}
\frac{\partial x}{\partial \varepsilon} \frac{\partial x}{\partial \eta} \\
\frac{\partial y}{\partial \varepsilon} \frac{\partial y}{\partial \eta}
\end{array}\right] .
$$

Equation (15) is integrated numerically by using a second order Gaussian quadrature in each direction. In general,

$$
\iint_{-1}^{1} g(\varepsilon, \eta) d \varepsilon d \eta=\sum_{i=1}^{4} g\left(\varepsilon_{i}, \eta_{i}\right) W_{i}
$$

where

\begin{tabular}{llll}
$\mathbf{i}$ & $\varepsilon_{\mathbf{i}}$ & $\eta_{\mathbf{i}}$ & Wi \\
\hline 1 & $-1 / \sqrt{3}$ & $-1 / \sqrt{3}$ & 1 \\
2 & $1 / \sqrt{3}$ & $-1 / \sqrt{3}$ & 1 \\
3 & $1 / \sqrt{3}$ & $1 / \sqrt{3}$ & 1 \\
4 & $-1 / \sqrt{3}$ & $1 / \sqrt{3}$ & 1
\end{tabular}

Upon integration of Eq. (15) for each element, the element equations are assembled to form the matrix Eq. (13). This equation is solved for the temperature field.

\subsection{Time Integration Scheme}

The time integration of Eq. (13) is carried out using a generalized trapezoidal method. This method has been shown by Hughes [2] to be unconditionally stable for nonlinear problems. The 
method consists of the following family array of algorithms: Find the temperature array, $\theta_{n}, n$ takes the value of $\{0,1, \ldots n\}$, after $n$ fixed-length time steps, $\Delta_{t}$, such that

$$
\begin{aligned}
& F_{n+\alpha}=C_{n+\alpha} \dot{\theta}_{n+\alpha}+H_{n+\alpha} \theta_{n+\alpha}, \\
& \theta_{n+1}={ }_{n}+\Delta t \dot{\theta} n+\alpha, \\
& \theta_{0}=\theta, \text { (initial condition) }
\end{aligned}
$$

where

$$
\begin{aligned}
& C_{n+\alpha}=C\left(\theta_{n+\alpha}, t_{n+a}\right), \\
& H_{n+\alpha}=H\left(\theta_{n+\alpha}, t_{n+a}\right), \\
& \theta_{n+\alpha}=(1-\alpha) \theta_{n}+\alpha \theta_{n+1}, \\
& F_{n+\alpha}=(1-\alpha) F_{n}+\alpha F_{n+1}, \\
& \frac{\partial \theta}{\partial t_{n+\alpha}}=\dot{\theta}_{n+\alpha}=(1-\alpha) \dot{\theta}_{n}+\alpha \dot{\theta}_{n+1}, \\
& t_{n+\alpha}=(n+\alpha) \Delta t .
\end{aligned}
$$

Equations (21b) and (21f) can be rephrased as

$$
\dot{\theta}_{n+\alpha}=\frac{1}{\Delta t}\left(\theta_{n+1}-\theta_{n}\right)
$$

and

$$
\theta_{n+\alpha}=\theta_{n}+\alpha\left(\theta_{n+1}-\theta_{n}\right)
$$

respectively. Substituting these equations into Eq. (21a) yields

$$
\left[\frac{C_{n+\alpha}}{\Delta t}+\alpha H_{n+\alpha}\right]\left\{\theta_{n+1}-\theta_{n}\right\}=\left\{F_{n+\alpha}-H_{n+\alpha} \theta_{n}\right\} \text {. }
$$


The solution marches forward in time by first solving Eq. (24) for the incremental temperature change vector $\left\{\theta_{n+1}-\theta_{n}\right\}$ and then updating the temperature. In nonlinear problems, $C, H$, and $F$ may be functions of $\theta$; thus, iteration must be used to solve Eq. (24) (see Section 3.12).

The parameter $\alpha$ used in transient conduction solutions, is taken to be in the interval $[0,1]$. Some well-known members of this $\alpha$-family are given below.

$\frac{\alpha}{0}$
$1 / 2$
$2 / 3$
1

Solution Method
Forward difference; forward Euler
Midpoint rule; Crank-Nicolson
Galerkin
Backward difference

In the case $\alpha=0$, the method is said to be explicit. For $\alpha<1 / 2$, the algorithm is conditionally stable; i.e., stability considerations limit the maximum time step size allowed. For $\alpha \geqq 1 / 2$, the algorithm is unconditionally stable and there are no time step restrictions.

For steady-state analysis, Eq. (13) reduces to

$$
[\mathrm{H}]\{\theta\}=\{\mathrm{F}\},
$$

and the solution is obtained in a single step. For nonlinear problems, iteration is used to solve Eq. (25) (see Section 3.12).

\subsection{Thermal Contact Resistance Across an Interface (Slidelines)**}

If two parts are placed in contact or across a small gap, there exists a considerable resistance to heat flow from one part to the other. This thermal resistance (known as "contact resistance") is a function of the gap width and gap filler, the physical properties of the contact material, the surface conditions and finish, the contact pressure, and the presence of a fluid or vacuum in the gap between the surfaces. We present an algorithm to couple the finite element heat transfer equations between two parts through a contact resistance across a gap which can be of zero thickness between the contacting surfaces. The surfaces in contact can have dissimilar zoning. For ease of presentation, assume for now that the gap has a finite thickness. It will be shown that the gap thickness factors out of the conductance matrix and is incorporated into a contact resistance term. This allows for a zero thickness gap both in reality (i.e., perfect thermal contact) and for numerical modeling purposes (i.e., the two contacting surfaces coincide in spacial coordinates). Triangles are used to mesh the gap between the contacting surfaces (Fig. 2-4).

\footnotetext{
${ }^{* *}$ Not validated yet in PC version.
} 


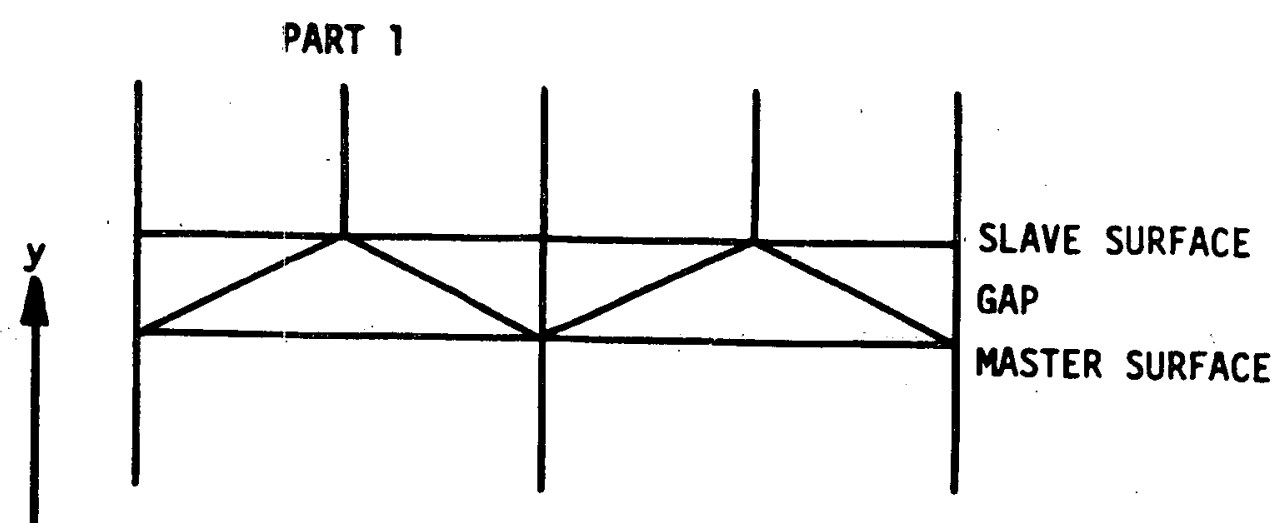

PART 2

Figure 2-4 Added elements for contact resistance or slideline. The gap elements are linear triangular elements (4) comprised of an orthotropic material. Consider
the triangular element, Fig. 2-5.

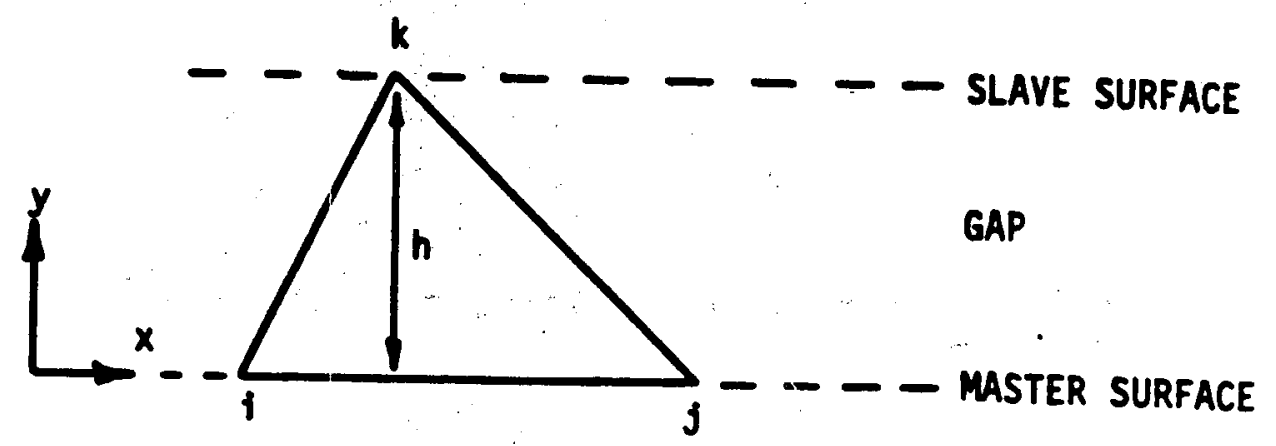

Figure 2-5 Typical triangular element at gap or slideline.

The element conductance matrix is defined as

$$
\mathrm{H}_{\mathrm{ij}}=\int_{\Omega} \nabla^{\mathrm{T}} \mathrm{N}_{\mathrm{i}} \mathrm{K} \nabla \mathrm{N}_{\mathrm{j}} \mathrm{d} \Omega,
$$

where

$$
N_{i}=\left(a_{i}+b_{i} x+c_{i} y\right) / 2 A_{i j k},
$$


in which

$$
\begin{aligned}
& a_{i}=x_{j} y_{k}-x_{k} y j \\
& b_{i}=y_{j}-y_{k} \\
& c_{i}=x_{k}-x_{j},
\end{aligned}
$$

with the other coefficients obtained by a cyclic permutation of subscripts in the order $\mathrm{i}, \mathrm{j}, \mathrm{k}$. The constitutive matrix is defined as

$$
K=\left[\begin{array}{ll}
\mathbf{k} & 0 \\
\mathbf{O} & \mathbf{0} \\
& \mathbf{k}_{\mathbf{y}}
\end{array}\right]
$$

Evaluating Eq. (26) using Eqs. (27)-(29) yields the element conductance matrix

$$
\begin{aligned}
H^{e} & =\frac{k_{x}}{4 A^{e}}\left[\begin{array}{lll}
b_{i} b_{i} & b_{i} b_{j} & b_{i} b_{k} \\
& b_{j} b_{j} & b_{j} b_{j} \\
s y m . & & b_{k} b_{k}
\end{array}\right] \\
& +\frac{k_{y}}{4 A^{e}}\left[\begin{array}{lll}
c_{i} c_{i} & c_{i} c_{j} & c_{i} c_{k} \\
& c_{j} c_{j} & c_{j} c_{k} \\
s y m . & & c_{k} c_{k}
\end{array}\right] .
\end{aligned}
$$

Heat transfer is assumed to take place only in the direction perpendicular to the contacting surfaces. Setting $\mathbf{k}_{\mathbf{x}}=0$, Eq. (30) becomes

$$
H^{e}=\frac{k_{y}}{4 A^{e}}\left[\begin{array}{lll}
c_{i} c_{i} & c_{i} c_{j} & c_{i} c_{k} \\
& c_{j} c_{j} & c_{j} c_{k} \\
s y m . & & c_{k} c_{k}
\end{array}\right]
$$

The area of the element is

$$
A^{e}=\frac{1}{2}\left(x_{j}-x_{i}\right) h=\frac{1}{2} c_{k} h .
$$


Substituting Eq. (32) into Eq. (31) yields the final result

$$
H^{e}=\frac{1}{2 c_{k} R}\left[\begin{array}{ccc}
c_{i} c_{i} & c_{i} c_{j} & c_{i} c_{k} \\
& c_{j} c_{j} & c_{j} c_{k} \\
& & \\
s y m . & & c_{k} c_{k} \cdot
\end{array}\right] \text {, }
$$

where

$$
\mathrm{R}=\frac{\mathrm{h}}{\mathrm{k}_{\mathrm{y}}}
$$

The term, $R$, is called the thermal contact resistance. As can be seen from Eqs. (33) and (34), the only place the gap thickness is represented is in the R term. A zero gap thickness is allowable (i.e., perfect thermal contact). However, for computer calculations, $\mathbf{R}$ would be assigned a small finite value to prevent a divide-by-zero in Eq. (33). Also, for numerical modeling purposes, the two contacting surfaces can spacially coincide, with the value assigned to $R$ representing the thermal resistance due to a physical gap. For axisymmetric problems, the triangle centroid radius, $r=1 / 3$ $\left(x_{i}+x_{j}+x_{k}\right)$, should be included in the numerator of Eq. (33).

If the contacting surfaces are at some angle, $\psi$, to the global coordinate system, a coordinate rotation must be performed prior to calculating the element conductance matrix, Eq. (33). A local coordinate system is defined with its origin fixed to the global coordinate system and with the $x \mid$ axis parallel to the contacting surfaces (Fig. 2-6). Local coordinates are calculated from the global coordinates by

$$
\begin{aligned}
& \mathrm{x}_{1}=\mathrm{x}_{\mathrm{g}} \cos \psi+\mathrm{y}_{\mathrm{g}} \sin \psi \\
& \mathrm{y}_{1}=-\mathrm{s}_{\mathrm{g}} \sin \psi+\mathrm{y}_{\mathrm{g}} \cos \psi
\end{aligned}
$$




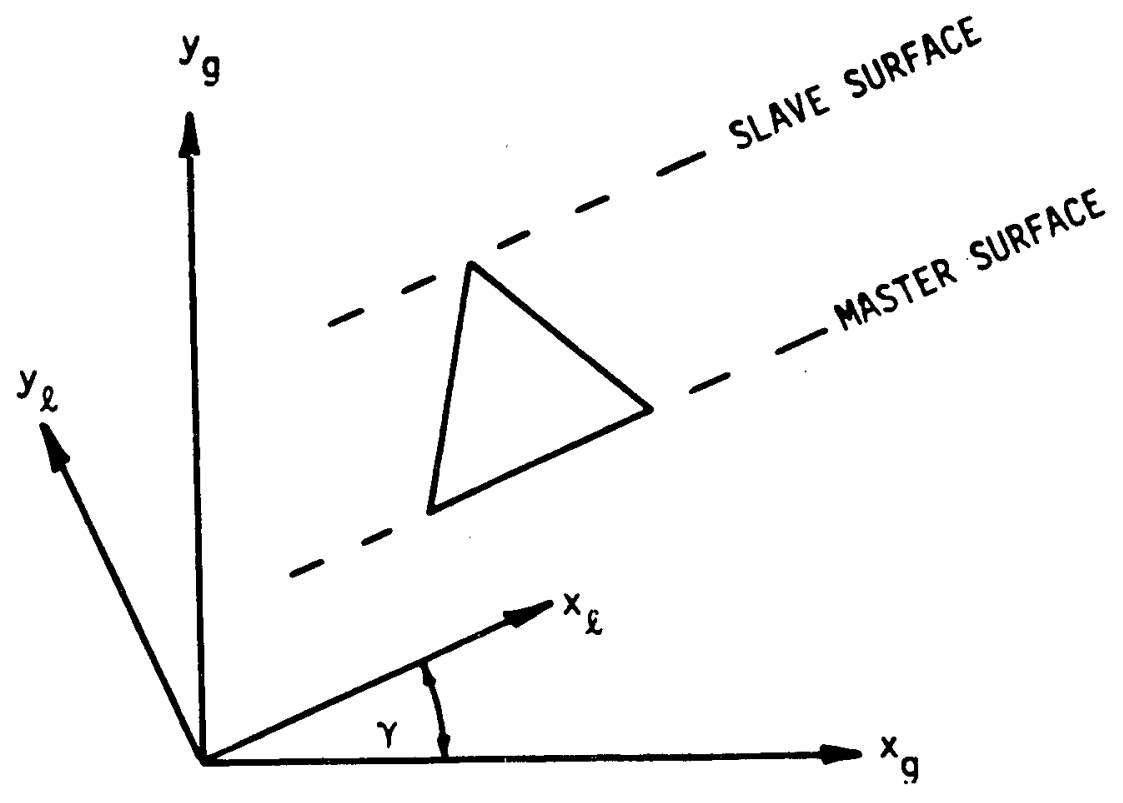

Figure 2-6 Relationship between local and global coordinates.

\subsection{Enclosure Radiation **}

The finite element thermal analysis of problems involving conduction in a solid coupled with thermal radiation in enclosures (cavities) within the solid can be performed using TOPAZ. The solution procedure is to solve the enclosure radiation problem first for the net radiative flux on each surface, using an estimated initial surface temperature distribution. The resulting fluxes are then used as boundary conditions for the solution of the conduction problem. The conduction solution then gives new estimates for the surface temperatures. The process is then repeated until temperature convergence is achieved.

The enclosure is defined by the discrete boundary surfaces of finite elements which surround the enclosure and define the solid object. Let the finite element of Fig. 2-7 be a boundary element comprising part of the wall of an enclosure. The boundary surface of this element is exchanging energy with other enclosure surfaces by radiation. Additionally, there may be heat transfer from the boundary surface by imposed heat flux or convection. Heat transfer by conduction is occurring within the body. A total energy balance across the boundary surface results in

$$
\dot{\mathrm{q}}_{\text {COND }}=\dot{\mathrm{q}}_{\mathrm{FLUX}}+\dot{\mathrm{q}}_{\mathrm{CONV}}+\dot{\mathrm{q}}_{\mathrm{RAD}} \text {. }
$$

\footnotetext{
** Not validated yet in $\mathrm{PC}$ version.
} 


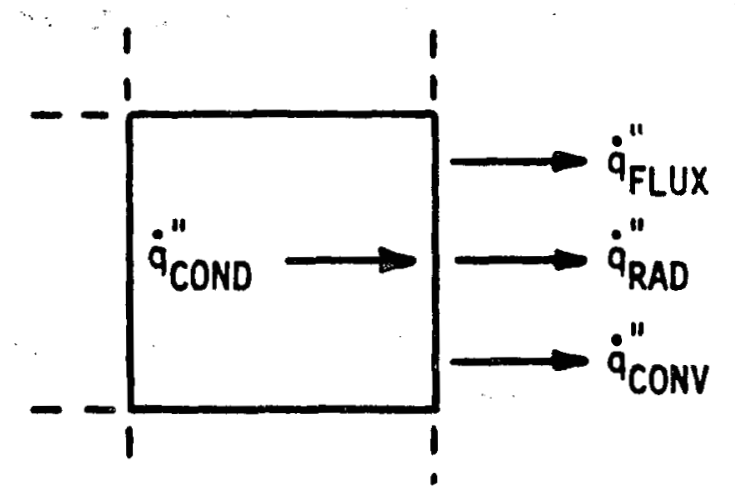

Figure 2-7 Boundary conductions at wall surface.

The radiation term may be calculated separately from any convection or conduction process if the medium within the enclosure does not absorb or emit radiant energy. In the radiation literature this is indicated by specifying

$$
\dot{\mathrm{q}}_{\mathrm{RAD}}=\dot{\mathrm{q}}_{\mathrm{NET}} \text {. }
$$

\section{Solution Using View Factors}

The net radiation heat flux at a surface $i$ is the difference between the emitted radiation and the absorbed portion of the incident radiation.

$$
\dot{\mathrm{q}}_{\mathrm{i}, \mathrm{NET}}^{\prime \prime}=\varepsilon_{\mathrm{i}} \sigma \mathrm{T}_{\mathrm{i}}^{4}+\alpha_{\mathrm{i}} \mathrm{H}_{\mathrm{i}},
$$

Note that Eq. (38) is not a total energy balance at the element surface. Equation (38) is only an expression for the radiation term, $\ddot{q}_{R A D}$, for use in Eq. (36).

The radiant flux incident on a surface, $\mathrm{H}_{\mathrm{i}}$ (called the irradiation), comes from the other surfaces of the enclosure. Consider the radiation coming from any surface $j$. An energy quantity called the radiosity,

$$
B_{j}=\varepsilon_{i} \sigma T_{i}^{4}+\rho_{i} H_{i}
$$


streams away from $\mathrm{j}$ in all directions. The first term on the right represents the radiation emitted by the surface, while the second term represents the reflected portion of the irradiation. Of this, an amount $A_{j} F_{j i} B_{j}$ arrives at surface $i$. By employing the reciprocity rule, $A_{j} F_{i j}=A_{j} F_{j i}$, this can be rephrased as $A_{i} F_{i j} B_{j}$. The rate at which energy arrives per unit area at $i$ from all $n$ surfaces of the enclosure is

$$
H_{i}=\sum_{j=1}^{n} F_{i j} B_{j}
$$

The radiosities are found by applying Eq. (39) at each surface of the enclosure. Using the gray body condition $\rho=1-\varepsilon$ at surface $i$,

$$
B_{i}=\varepsilon_{i} \sigma T_{i}^{4}+\left(1+\varepsilon_{i}\right) H_{i}
$$

Then, using Eq. (40),

$$
B_{i}=\varepsilon_{i} \sigma T_{i}^{4}+\left(1-\varepsilon_{i}\right) \sum_{j=1}^{n} F_{i j} B_{j}
$$

In this way there are generated $\mathrm{n}$ linear algebraic equations for the $\mathrm{n}$ unknown radiosities. The system of Eq. (42) can be rephrased as

$$
[\chi]\{B\}=\{\tau\}
$$

in which

$$
\begin{aligned}
& \chi_{i j}=\frac{\delta_{i j}-\left(1-\varepsilon_{i}\right) F_{i j}}{\varepsilon_{i}}, \\
& \tau_{i}=\sigma T_{i}^{A}
\end{aligned}
$$

The radiosities are then calculated by

$$
\{B\}=[\chi]^{-1}\{\tau\}
$$

If the surface emissivities are not a function of temperature, then the terms in $[\chi]$ are constant. Thus, the inverse matrix, $[\chi]^{-1}$, need only be calculated once for the problem. 
The solution of the enclosure radiation problem proceeds as follows:

1. Compute $[\chi]$.

2. Compute $[\chi]^{-1}$.

3. Guess an initial temperature distribution $(B)=[\chi]^{-1}(T)_{k}$.

4. Compute $\{B\}=[\chi]^{-1}\{\tau]_{k}$.

5. For $\mathrm{i}=1,2, \ldots, \mathrm{n}$ do:

$$
\begin{array}{ll}
\text { Compute } & \mathrm{H}_{\mathrm{i}}=\frac{1}{1-\varepsilon_{\mathrm{i}}}\left(\mathrm{B}_{\mathrm{i}}-\varepsilon_{\mathrm{i}} \sigma \mathrm{T}_{\mathrm{i}}^{4}\right), \\
\text { Compute } \quad \dot{\mathrm{q}}_{\mathrm{i}, \mathrm{NET}}=\varepsilon_{\mathrm{i}} \sigma \mathrm{T}_{\mathrm{i}}^{4}-\alpha_{\mathrm{i}} \mathrm{H}_{\mathrm{i}} .
\end{array}
$$

6. Solve the conduction problem for $\{t\}_{k=k+1}$ using $\left(\ddot{q}_{\text {NET }}\right\}$.

7. Repeat steps 4 to 6 until the following criteria are satisfied for prescribed $\varepsilon$ :

$$
\frac{\operatorname{ABS}\left(\left\|T_{k+1}\right\|_{2}-|| T_{k} \|_{2}\right)}{\left\|T_{k+1}\right\|_{2}} \leq \bar{\varepsilon}
$$

The finite element conduction problem is solved using

$$
\dot{\mathrm{q}}_{\mathrm{i}, \mathrm{NET}}^{\prime \prime}=\varepsilon_{\mathrm{i}} \sigma \mathrm{T}_{\mathrm{i}}^{4}+\alpha_{\mathrm{i}} \mathrm{H}_{\mathrm{i}} \text {, }
$$

from step 5 as a boundary condition. The $\mathrm{T}_{1}^{4}$ term is linearized by using the first two terms of its Taylor series expansion about $\hat{T}_{i}$, the temperature from the previous iteration.

$$
T_{i}^{4}=4 A_{i}^{3} T_{i}-34_{i}^{4} .
$$

Using Eq. (46) in Eq. (45),

$$
\dot{q}_{i}^{\prime \prime}{ }_{N E T}=4 \varepsilon_{i} \sigma \hat{T}_{i}^{3} T_{i}-3 \varepsilon_{i} \sigma \hat{T}_{i}^{4}-\alpha_{i} H_{i} .
$$
The first term on the right contributes to the conductance matrix, while the second and third terms
contribute to the load vector. 
TOPAZ can also solve the coupled problem using exchange factors, $F_{i j}$. The exchange factor is a characterization of the effect of the system geometry, emissivity, and reflectivity on the capability of radiative transport between surfaces $A_{i}$ and $A_{j}[3]$.

Using exchange factors, the net radiative heat flux at a surface $i$ is

$$
\begin{aligned}
\dot{q}_{i, N E T} & =\sum_{j} F_{i j}\left(E_{i}-E_{j}\right) \\
& +\left(\sum_{j} F_{i j}-F_{i i}\right) \sigma T_{i}^{4}-\sum_{\substack{j \\
i \neq j}} F_{i j} \sigma T_{i}^{4}
\end{aligned}
$$

Following the previous procedure, $\mathrm{T}_{1}^{4}$ is linearized, and contributions to the conductance matrix and load vector are obtained.

\section{Wavelength-dependent Properties}

The gray body assumption becomes prone to error when the range of wavelengths contains strong emission bands, such as for metals. TOPAZ solves problems with wavelength-dependent properties by subdividing the wavelength range into several finite bands and assuming that the surfaces are gray within each band [4]. The net radiative heat flux at a surface $i$ is

$$
\dot{\mathrm{q}}_{\mathrm{i}, \mathrm{NET}}=\int_{\lambda} \dot{\mathrm{q}}_{\mathrm{i} \lambda, \mathrm{NET}},
$$

with

$$
\dot{\mathrm{q}}_{\mathrm{i}, \mathrm{NET}}=\sigma \mathrm{E}_{\mathrm{i}, \mathrm{b} \lambda}-\alpha_{\mathrm{i} \lambda} \cdot \mathrm{H}_{\mathrm{i} \lambda}
$$

using view factors or, using exchange factors,

$$
\dot{q}_{i \lambda, N E T}=\sum_{j} F_{i j, \lambda}\left(E_{i, b \lambda}-E_{j, b \lambda}\right) .
$$

The black body band emissive power is calculated by

$$
E_{b \lambda}=E_{b \lambda}(\Delta \lambda, T)=f \sigma T^{4} .
$$


The term $\mathrm{f}$ represents the fraction of the total radiant output of a black body that is contained in the wavelength band $\Delta \lambda=\lambda_{2}-\lambda_{1}$,

$$
f(\Delta \lambda, T)=F_{0-\lambda_{2} T}-F_{0-\lambda i} T,
$$

with [12]

$$
\begin{aligned}
& F_{0-\lambda T}=\frac{15}{\pi^{4}} \quad m=1,2, \ldots \frac{e^{-m v}}{m^{4}}\{[(m v+3) m v+6] m v+6\} \quad v \geq 2, \\
& F_{0-\lambda T}=1-\frac{15}{\pi^{4}} v^{3}\left(\frac{1}{3}-\frac{v}{8}+\frac{v^{2}}{60}-\frac{v^{4}}{5040}+\frac{v^{6}}{272160}-\frac{v^{8}}{13305600}\right) v<2,
\end{aligned}
$$

where

$$
\left.v=\frac{14388}{\lambda t} \text { (units: } \lambda[\mu \mathrm{m}]: T[K]\right) \text {. }
$$




\subsection{ASPECTS OF TOPAZ}

The sections in this chapter should be consulted prior to and during the construction of TOPAZ input. Many helpful suggestions, warnings, and procedural information are contained in each section.

\subsection{Bandwidth Minimization}

The Gibbs-Poole-Stockmeyer algorithm [5] coded by S. J. Sackett is available as an option in TOPAZ to minimize the bandwidth and profile of the conductance matrix. The result of bandwidth minimization is a decrease in problem solution time. Bandwidth minimization node-renumbering is transparent to the user. All calculated nodal quantities are printed using the user's original nodenumbering scheme.

\subsection{Boundary Conditions}

As discussed in Section 2.2 , heat flux boundary conditions, $\ddot{\mathrm{q}}$, on the boundary are represented by

$$
\mathrm{k}_{\mathrm{x}} \frac{\partial \theta}{\partial \mathrm{x}} \mathrm{n}_{\mathrm{x}}+\mathrm{k}_{\mathrm{y}} \frac{\partial \theta}{\partial \mathrm{y}} \mathrm{n}_{\mathrm{y}}=\gamma-\beta\left(\theta-\theta_{\beta}\right)=\dot{\mathrm{q}} .
$$

Heat flow is positive in the direction of the surface outward normal vector. Surface definition is in accordance with the right-hand rule. The outward normal vector points to the right as one progresses from node $\mathrm{N}_{1}$ to $\mathrm{N}_{2}$ (Fig. 3-1).

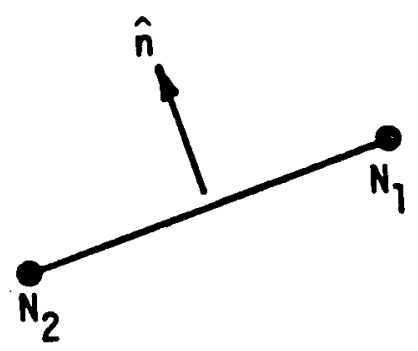

Figure 3-1 Direction of outward normal vector with respect to nodes.

Boundary conditions can be functions of temperature or time. More than one boundary condition can be specified over the same surface, such as in a case of combined convection and radiation. For situations where it is desired to specify adiabatic (i.e., $q^{\prime \prime}=0$ ) conditions such as at an insulated surface or on a line of symmetry no boundary condition need be specified. This is the default boundary condition in TOPAZ. 


\section{Temperature}

Temperature boundary conditions can be specified on any node, whether on the physical boundary or not.

Flux

Set $\ddot{q}=q_{f}$ where $\mathrm{q}_{f}$ is defined at the node points comprising the flux b.c. segments (Fig. 3-2).

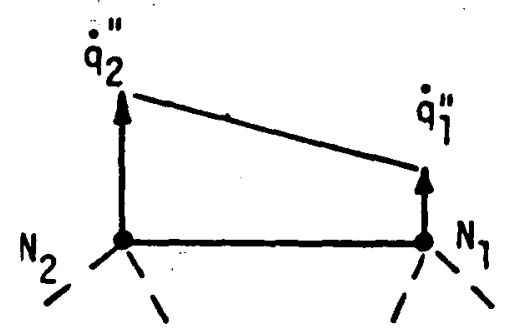

Figure 3-2 Setting boundary linearly varying flux boundary conditions on surface segment.

\section{$\underline{\text { Radiation }}$}

A radiation boundary condition is calculated using a radiant-heat-transfer coefficient. Set $\ddot{q}=h_{r}$ $\left(T-T_{\infty}\right)$ where $h_{r}$ is a radiant-heat-transfer coefficient defined as

$$
\mathrm{h}_{\mathrm{r}}=\sigma F\left(\mathrm{~T}+\mathrm{T}_{\infty}\right)\left(\mathrm{T}^{2}+\mathrm{T}_{\infty}^{2}\right)
$$

The exchange factor, $F$ is a characterization of the effect of the system geometry, emissivity, and reflectivity on the capability of radiative transport between surfaces. The radiation b.c. data cards require specification of the product, $\mathrm{f}=\sigma F$, and $\mathrm{T}_{\infty}$ for the boundary segment.

\section{Convection}

$$
\text { Set } \ddot{q}=h_{c}\left(T-T_{\infty}\right)^{\mathbf{a}}\left(\left(\Gamma-T_{\infty}\right)\right. \text {, }
$$

where

$$
\begin{array}{lll}
\mathrm{h}_{\mathrm{C}} & =\text { heat transfer coefficient, } \\
\left(\mathrm{T}-\mathrm{T}_{\infty}\right)^{\mathrm{a}} & = & \text { free convection témperature dependence, } \\
\left(\mathrm{T}-\mathrm{T}_{\infty}\right) & = & \text { temperature potential. }
\end{array}
$$


TOPAZ evaluates $h_{\mathcal{C}}$ at the film temperature

$$
\mathrm{T}_{\mathrm{f}}=\frac{1}{2}\left(\mathrm{~T}_{\mathrm{SURF}}+\mathrm{T}_{\infty}\right)
$$

For forced convection calculations, set $\mathrm{a}=0$. Then $\ddot{q}=\mathrm{hc}\left(T-\mathrm{T}_{\infty}\right)$

For free convection calculations, empirical formulas are available to calculate the heat transfer coefficient. These formulas contain the Grashof number raised to some power, a. For example, the average value of the heat transfer coefficient for laminar free convection from an isothermal vertical plate of length $\mathrm{L}$ is

$$
\mathrm{h}_{\mathrm{c}}=\frac{0.555 \mathrm{k}_{\mathrm{f}} \mathrm{Pr}^{1 / 4} \mathrm{Gr}_{\mathrm{L}}^{1 / 4}}{\mathrm{~L}},
$$

where the Grashof number is

$$
G r_{L}=\frac{g \beta_{f}\left(T-T_{\infty}\right) L^{3}}{v_{f}^{2}}
$$

The rate of heat transfer by convection between the plate and a fluid may be computed by the relation

$$
\begin{aligned}
. \ddot{q} & =h\left(T-T_{\infty}\right) \\
& =0.555 \frac{k_{f}}{L}\left(\frac{P_{r} g \beta_{f} L^{3}}{v_{f}^{2}}\right)^{1 / 4} \quad\left(T-T_{\infty}\right)^{1 / 4}\left(T-T_{\infty}\right) .
\end{aligned}
$$

The term

$$
=0.555 \frac{k_{f}}{L}\left(\frac{P_{r} g \beta_{f} L^{3}}{v_{f}^{2}}\right)^{1 / 4}
$$

contains constants and material properties which may be a function of temperature. Let $h$ on the convection boundary-condition data-card represent this term. Give the free convection exponent, a, on this data-card a value of 0.25 to account for the term $\left(T-T_{\infty}\right)^{1 / 4}$. 


\subsection{Bulk Fluid**}

The bulk fluid concept is best described with the aid of Fig. 3-3:

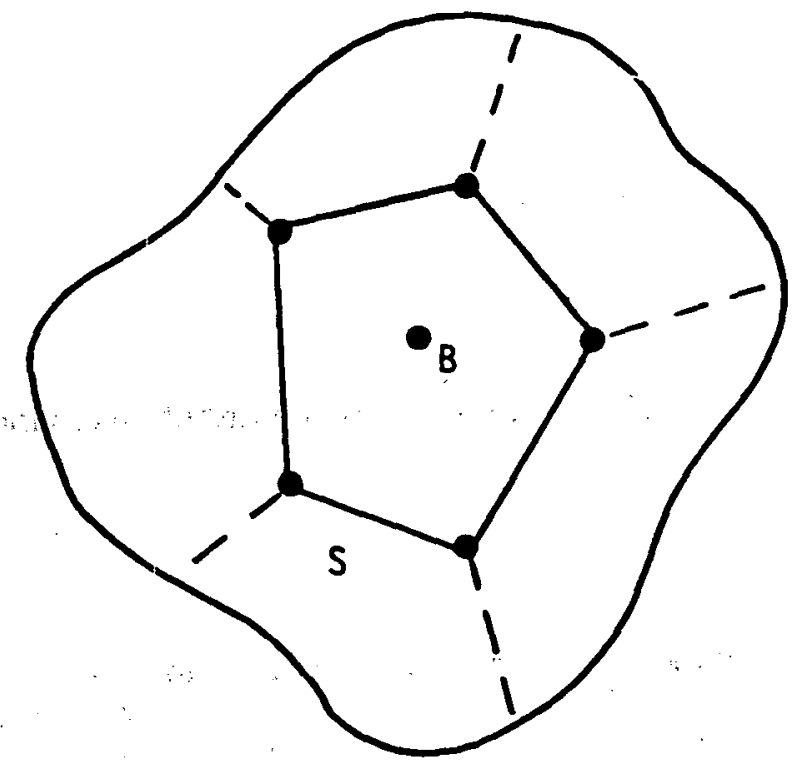

Figure 3-3 Heat flow between bulk node (B) and adjoining surface (S).

Here a bulk node " $\mathrm{B}$ " is used to represent the entire volume of a particular material, such as a gas in a cavity. The heat flow between the bulk node (material) " $\mathrm{B}$ " and an adjoining surface " $\mathrm{S}$ " is given by

$$
q^{\prime \prime}=f(\theta, t)\left(\theta_{S}^{a}-\theta_{B}^{a}\right)_{b},
$$

where $\theta_{S}$ and $\theta_{B}$ represent the temperatures of the surface "S" and the bulk node "B," respectively. In addition, the density, specific heat, and volume of the bulk material are specified.

TOPAZ requires that a bulk node be given a node number as well as coordinates. However, these coordinates are arbitrary.

The bulk node concept can also be used in the case where it is desired to specify a lumped heat capacity at a node. In such a case, no segments " $S$ " are associated with the bulk node, and only the density, heat capacity, and volume associated with the bulk node are specified.

\footnotetext{
${ }^{* *}$ Not validated yet in $\mathrm{PC}$ version.
} 


\subsection{Element Types}

A four node isoparametric element is used. This element degenerates to a three node triangle when the last two node numbers of the four node elements are identical (Fig. 3-4).
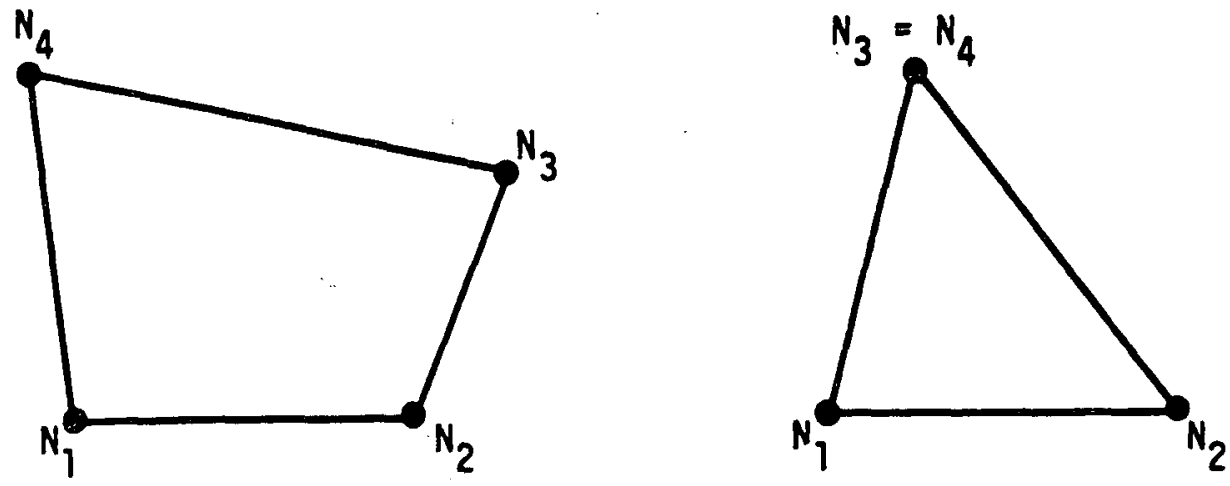

Figure 3-4 Degeneration from four node into three node element.

\subsection{Energy Balances**}

Various energy terms may be printed and written into the plot file for post processing. The energy terms are:

- change in material internal energy for time step,

- change in material internal energy from initial time,

- heat transfer rates on boundary condition surfaces,

- heat transfer rates on enclosure radiation surfaces, and

- $\mathrm{x}$ and $\mathrm{y}$ fluxes at all nodes.

Since the nodal fluxes are expensive to calculate, a flag on data section 1 is available to turn this option on or off.

\subsection{Function Definitions}

Any specified function of time or temperature (for example, internal hear generation, boundary conditions) can be described by either a piece-wise linear curve or by a functional relationship defined in a user subprogram. Functions that are dependent upon both time and temperature must be defined by a User Subprogram.

\footnotetext{
** Not validated yet in PC version.
} 
A typical piecewise linear curve is shown below in Fig. 3-5.

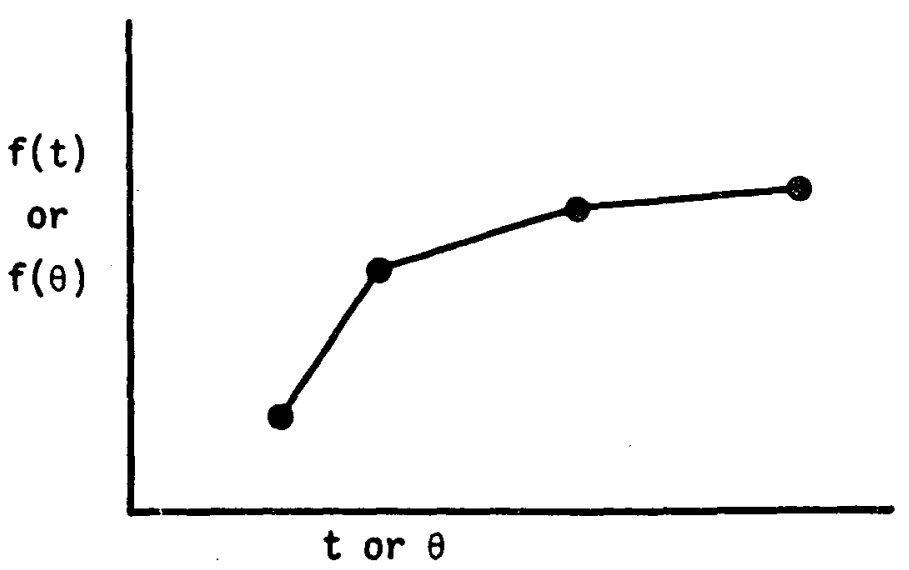

Figure 3-5 Piecewise linear curve for interpolation.

Values of a function at intermediate points on a curve are obtained by linear interpolation. Functional values outside the range of a curve are extrapolated equal to the last value or first value in function curve tables.

A single curve may be used for several functions if their ordinates differ by only a constant. This is accomplished by the use of curve multipliers which are applied to the ordinate of the curve.

In order to differentiate between a function of time and a function of temperature, the sign on the number assigned to the curve describing the function is used. For a time variation, the curve number is positive and for a temperature variation, the curve number is preceded by a negative sign. A curve number of zero indicates that a function is constant.

\subsection{Heat Generation}

Volumetric heat generation rates may be specified by element, by material, or both (in which case the effect is additive). Volumetric heat generation rates can be functions of time or temperature (see Section 3.6). Spatially, they are assumed constant within an element.

\subsection{Initial Conditions}

Initial temperature conditions can be specified on the nodal data-input cards or on the nodal temperature initial-condition cards. If no temperatures are specified, the default is 0 . For nonlinear steady-state problems, the temperature initial condition serves as a first guess for the equilibrium iterations (see Section 3.12). 


\subsection{Internal Boundary Elements**}

Internal boundary elements allow thermal coupling between two surfaces (e.g., across a gap between two parts) according to the formula

$$
q=f(q, t)\left(\theta_{S}^{a}-\theta_{B}^{a}\right) b .
$$

The subscripts A and B refer to the element segments as indicated in Fig. 3-6.

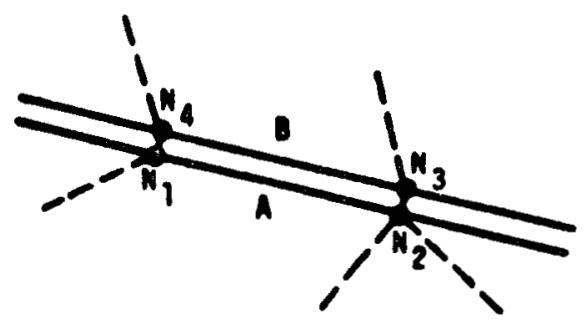

Figure 3.6 Thermal coupling between two surfaces.

$\theta_{A}$ and $\theta_{B}$ are the respective average temperatures of these surfaces. Energy transport is normal to surface A. Segments A and B should be approximately the same length. While four node numbers are required to define this element, opposed nodal coordinates may coincide. That is, an element may have zero thickness. This element is suitable for specifying contact resistances between surfaces and for describing certain types of gaps between surfaces.

\subsection{Material Properties}

The density, heat capacity, and thermal conductivity are assumed to be spatially constant within each element. Heat capacity and thermal conductivity may be functions of temperature. Since the density and heat capacity appear only as a product in the governing equations, the temperature dependence of the density may be included in the temperature dependence of the heat capacity.

The thermal conductivity may be either isotropic or orthotropic. The orthotropic material angle $\psi$ is defined as shown in Fig. 3-7 below. The orthotropic thermal conductivity matrix, K, is

$$
K=\left[\begin{array}{cc}
k_{m 1} \cos ^{2} \psi+k_{m 2} \sin ^{2} \psi & \left(k_{m 1}-k_{m 2}\right) \sin \psi \cos \psi \\
\left(k_{m 1}-k_{m 2}\right) \sin \psi \cos \psi & k_{m 1} \sin ^{2} \psi+k_{m 2} \cos ^{2} \psi
\end{array}\right] \text {. }
$$

\footnotetext{
** Not validated yet in PC version.
} 


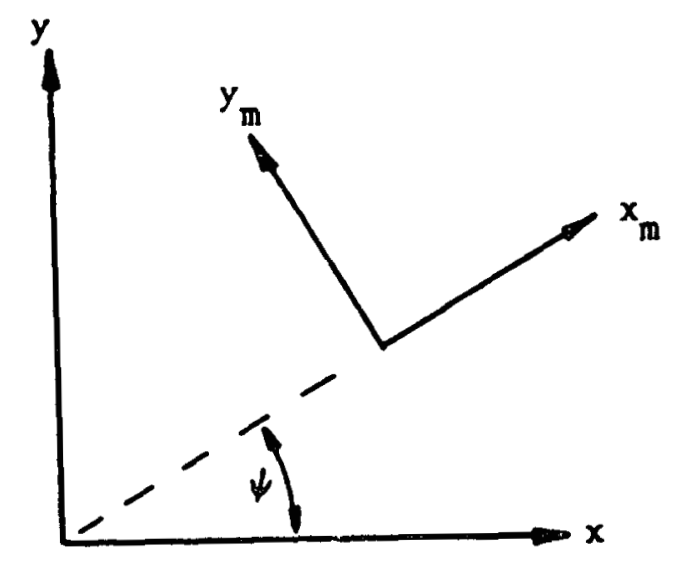

Figure 3.7 Orthotropic material angle $\psi$.

\subsection{Mesh Generation}

TOPAZ has no general mesh generation capability. Rows of evenly spaced nodes and rows of sequential elements may be generated internal to the code.

\subsection{Nonlinear Analysis}

In a nonlinear problem, $\mathrm{C}, \mathrm{H}$, and $\mathrm{F}$ may be functions of $\theta$, and iteration is required to solve Eq. (24). Functional iteration with under relaxation is used. The nonlinear solution scheme consists of two steps. The first step called "reformation" is the assembly and triangularization of the coefficient matrix

$$
\left[\frac{\mathrm{C}+\mathrm{a}}{\Delta \mathrm{t}} \pm \alpha K_{n+a}\right]
$$

in Eq. (24). This step is computationally expensive. The second step called an "equilibrium iteration" is the formation of the right-hand side vector $\left\{F-K_{n+\alpha} \theta_{n}\right\}$ in Eq. (24) and back substitution to solve for $\left\{\theta_{n+1}-\theta_{n}\right\}$. This step is computationally inexpensive.

For strongly nonlinear problems (e.g., radiation boundary conditions), it is necessary to perform a reformation for each equilibrium iteration. For weakly nonlinear problems (e.g., material property nonlinearities), it is computationally advantageous to perform a reformation only at the beginning of the time step, and then to perform as many equilibrium iterations as required for convergence. Further still, a reformation of Eq. (69) can be performed and used over several time steps. It is best to base on experience or a trial-and-error process the decision as to the number of reformations and equilibrium iterations to use on a particular problem. 
In a steady-state nonlinear problem, an initial guess should be made of the final temperature distribution and included in the input file as an initial condition. If your guess is good, a considerable savings in computation time is achieved.

\subsection{Phase Change}

A phase change algorithm developed by Rolph and Bathe [6] has been implemented in TOPAZ. This algorithm explicitly constrains the solution of the conduction problem to satisfy phase change energy balance. Therefore, the finite element mesh and time step size for a specific analysis can be largely chosen by considering the accuracy predicted on the temperatures when phase changes are neglected. The phase change front may advance over several elements in a single time step.

A solution may show temperature oscillations at nodes near the phase change front. This is a result of the algorithm not following the phase change front but, rather, detecting phase change within an element and then lumping material latent heat at the nodes. Spacial discretization and time step size will effect the magnitude and decay rate of these temperature oscillations.

Phase change problems require specification of the problem as a nonlinear analysis with backward difference time integration $(\alpha=1)$ These conditions are automatically invoked on the analysis by setting the phase change calculation flag on control-card one.

\subsection{Post Processing}

The post processor code PLOTTER in SCANS is available to produce temperature contour plots, flux contour plots, temperature-time history plots, plots of temperature vs distance along arbitrary cut lines, and various geometry plots.

\subsection{Radiation in Enclosures"*}

The theory and algorithms used for enclosure radiation problems are presented in Section 2.5. An enclosure is defined by the discrete surfaces which are, in general, the boundaries of the finite elements which surround the enclosure, as illustrated in the following Fig. 3-8.

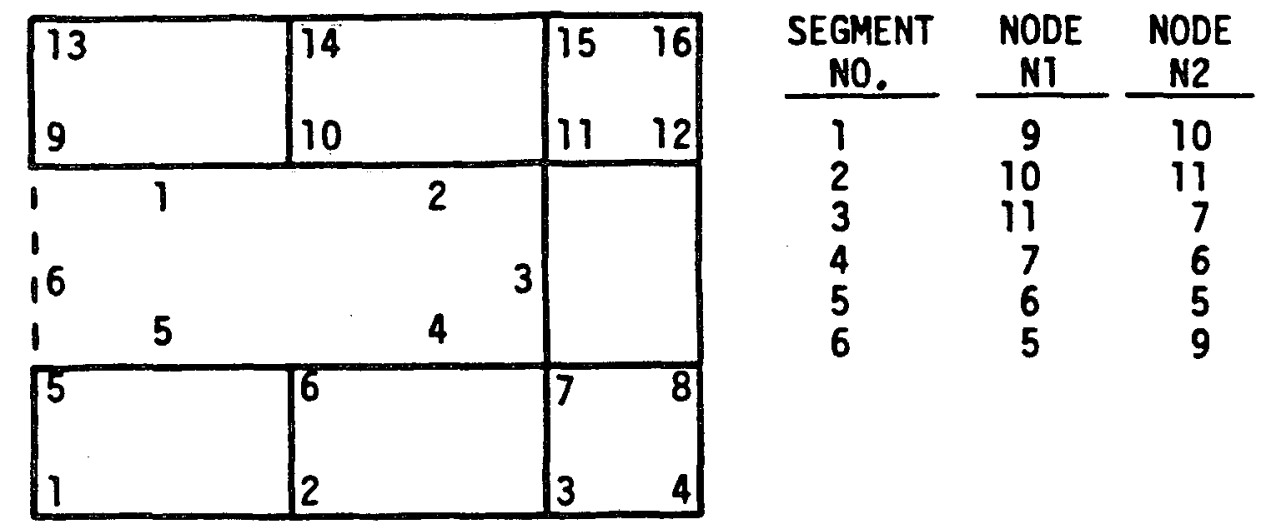

Figure 3-8 Relationship of boundaries for an enclosure.

\footnotetext{
** Not validated yet in $\mathrm{PC}$ version.
} 
The enclosure segments must be specified such that the surface outward normal vector points to the right as one proceeds from node $\mathrm{N}_{1}$ to $\mathrm{N}_{2}$ in Fig. 3-8.

When an enclosure has an opening to the exterior of a body, such as surface 6 in Fig. 3-8, the opening acts like a nonflective surface. Such a surface acts as a blackbody radiator $(\varepsilon=1)$ at the outer surrounding temperature. Such surfaces are identified on the enclosure radiation data-cards by flagging them as not participating in the conduction part of the problem and giving them an emissivity curve number of zero.

Emissivity is input as a function of wavelength. If emissivity is considered not a function of wavelength, the first wavelength breakpoint, $\lambda$, should be assigned a large number (e.g., $1 \times 10^{10}$ ). Note that the units on the wavelength must be micrometers.

Enclosure radiation problems can be expensive to solve both in computation time and computer core requirements. Problems using view factors that are not a function of wavelength are relatively quick because the $[\chi]$ matrix has to be formed only once for the problem. Problems using wavelength dependent emissivities are computationally slower because a Gauss-Seidel iterative solution is performed to solve the radiation part of the coupled problem for each wavelength band. The radiation part of the coupled problem is performed in-core. For very large problems, an out-of-core solution is available. Contact the author for further information.

\subsection{Slidelines - Thermal Contact Resistance Across an Interface**}

The theory and algorithm used for slidelines is presented in Section 2.4. Slidelines are used to couple the finite element heat transfer equations between two parts through a thermal contact resistance across a gap between the contacting surfaces. The surfaces in contact can coincide spatially and have dissimilar zoning. One side of the contact surface is referred to as the master surface, and the other side is referred to as the slave surface. The designation of the slave and master surface is arbitrary. However, the slave surface must lie to the left of the master surface, as one moves along the master surface, encountering the master nodes in the order that they are defined (Fig. 3-9).

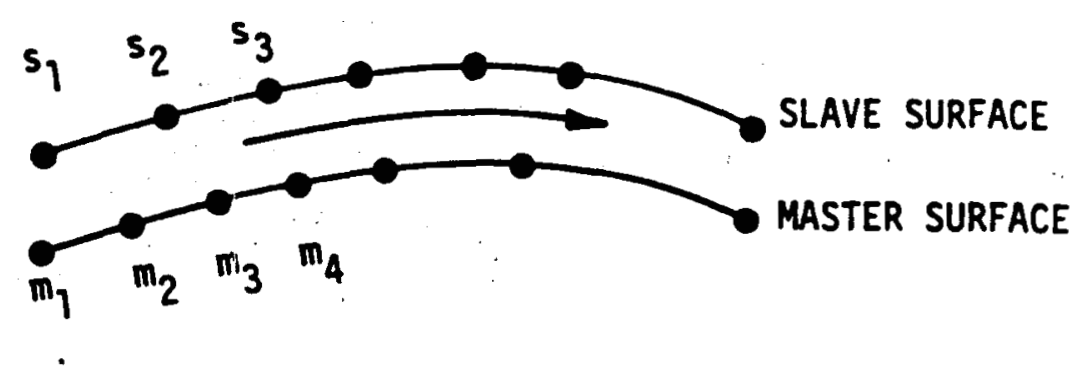

Figure 3-9 Relationship between slave and master surfaces.

\footnotetext{
** Not validated yet in $\mathrm{PC}$ version.
} 


\subsection{Steady-State Analysis}

TOPAZ has a one step steady-state solution algorithm. For nonlinear steady-state problems, iteration is required, and an initial guess of the temperature field is needed. This can be specified on the initial temperature condition data-cards.

\subsection{Thermal Stress Analysis}

The temperatures calculated by TOPAZ can be used in performing uncoupled thermal stress analyses with the mechanical code SAPPHIRE (which is included in SCANS). SAPPHIRE will read the temperature states from the plot files generated by TOPAZ.

\subsection{Transient Analysis}

TOPAZ has both fixed and variable time-step capabilities. In addition, any number of fixed timestep blocks may be specified, allowing for variation of time-step size in a stepwise fashion by restarting the code with new initial temperatures.

\subsection{Units}

Any consistent set of units may be used with the governing equations.

Examples are:

Quantity
Temperature
Space
Time
Density
Heat capacity
Thermal conductivity
Thermal generation
Heat flux

\begin{tabular}{lll}
\multicolumn{3}{c}{ Units } \\
\hline $\mathrm{C}$ & $\mathrm{C}$ & $\mathrm{F}$ \\
$\mathrm{m}$ & $\mathrm{cm}$ & $\mathrm{in}$ \\
$\mathrm{s}$ & $\mathrm{s}$ & $\mathrm{min}^{*}$ \\
$\mathrm{~kg} / \mathrm{m}^{3}$ & $\mathrm{~g} / \mathrm{cm}^{3}$ & $\mathrm{Lb}_{\mathrm{m}} / \mathrm{in}^{3}$ \\
$\mathrm{~J} / \mathrm{kg} \mathrm{C}$ & $\mathrm{cal} / \mathrm{g} \mathrm{C}$ & $\mathrm{Btu} / \mathrm{Lb}_{\mathrm{m}} \mathrm{F}^{*}$ \\
$\mathrm{~W} / \mathrm{m} \mathrm{C}$ & $\mathrm{cal} / \mathrm{s} \mathrm{cm} \mathrm{C}$ & $\mathrm{Btu} / \mathrm{min} \mathrm{in} \mathrm{F}^{*}$ \\
$\mathrm{~W} / \mathrm{m}^{3}$ & $\mathrm{cal} / \mathrm{s} \mathrm{cm}^{3}$ & $\mathrm{Btu} / \mathrm{min} \mathrm{ft}^{3}$ \\
$\mathrm{~W} / \mathrm{m}^{2}$ & $\mathrm{cal} / \mathrm{s} \mathrm{cm}^{2}$ & $\mathrm{Btu} / \mathrm{min} \mathrm{ft} \mathrm{f}^{*}$
\end{tabular}

* SCANS Units 


\subsection{EXAMPLES}

\subsection{Introduction}

To validate TOPAZ, six sample problems similar to shipping cask geometry or thermal loadings were run. These sample problems are documented in this manual. Two additional problems benchmark TOPAZ results from SCANS with the mainframe version of TOPAZ.

\subsection{Example 1 - Finite Cylinder with Two Surface Temperatures}

Carslaw and Jaeger [7] provide a solution for steady-state heat flow in a solid cylinder (Fig. 4-1) with the temperature on the bottom at a fixed temperature and the side and the top at a different temperature. The material thermal properties are held constant (see Fig. 4-1 and Table 4-1). This two-dimensional problem has the exact analytical solution (see Fig. 4-2).

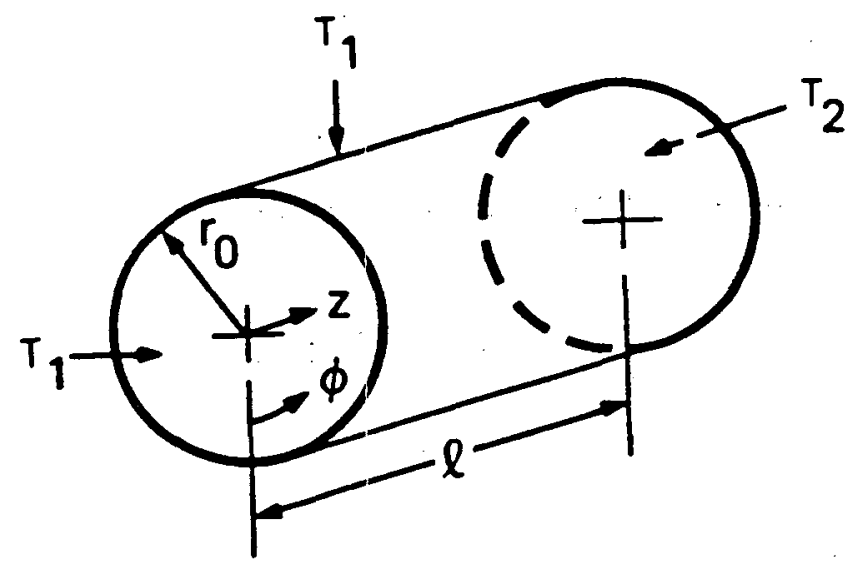

$$
\begin{array}{ll}
\mathrm{T}=\mathrm{T}_{1}, & \mathrm{z}=0 . \\
\mathrm{T}=\mathrm{T}_{1}, & \mathrm{r}=\mathrm{r}_{0} . \\
\mathrm{T}=\mathrm{T}_{2}, & \mathrm{z}=1 .
\end{array}
$$

Figure 4-1 Solid finite cylinder with two surface temperatures.

$$
\begin{aligned}
& \frac{T-T_{1}}{T_{2}-T_{1}}=2 \sum_{n=1}^{\infty} \frac{\sinh \left(\lambda_{n} Z\right) J_{0}\left(\lambda_{n} R\right)}{\lambda_{n} \sinh \left(\lambda_{n} L\right) J_{1}\left(\lambda_{n}\right)} \\
& J_{0}\left(\lambda_{n}\right) \quad=0, \mathrm{Z}=\mathrm{z} / \mathrm{r}_{0}, \mathrm{~L}=1 / \mathrm{r} 0
\end{aligned}
$$


Table 4-1 Input data for Example 1.

Geometry

$$
\begin{aligned}
1 & =10.87313 \mathrm{~m} \\
r_{0} & =2.71828 \mathrm{~m}
\end{aligned}
$$

Boundary Conditions

$\mathrm{T}_{2}=10^{\circ} \mathrm{C}$, bottom surface temperature

$\mathrm{T}_{1}=0^{\circ} \mathrm{C}$, top/side surface temperature 

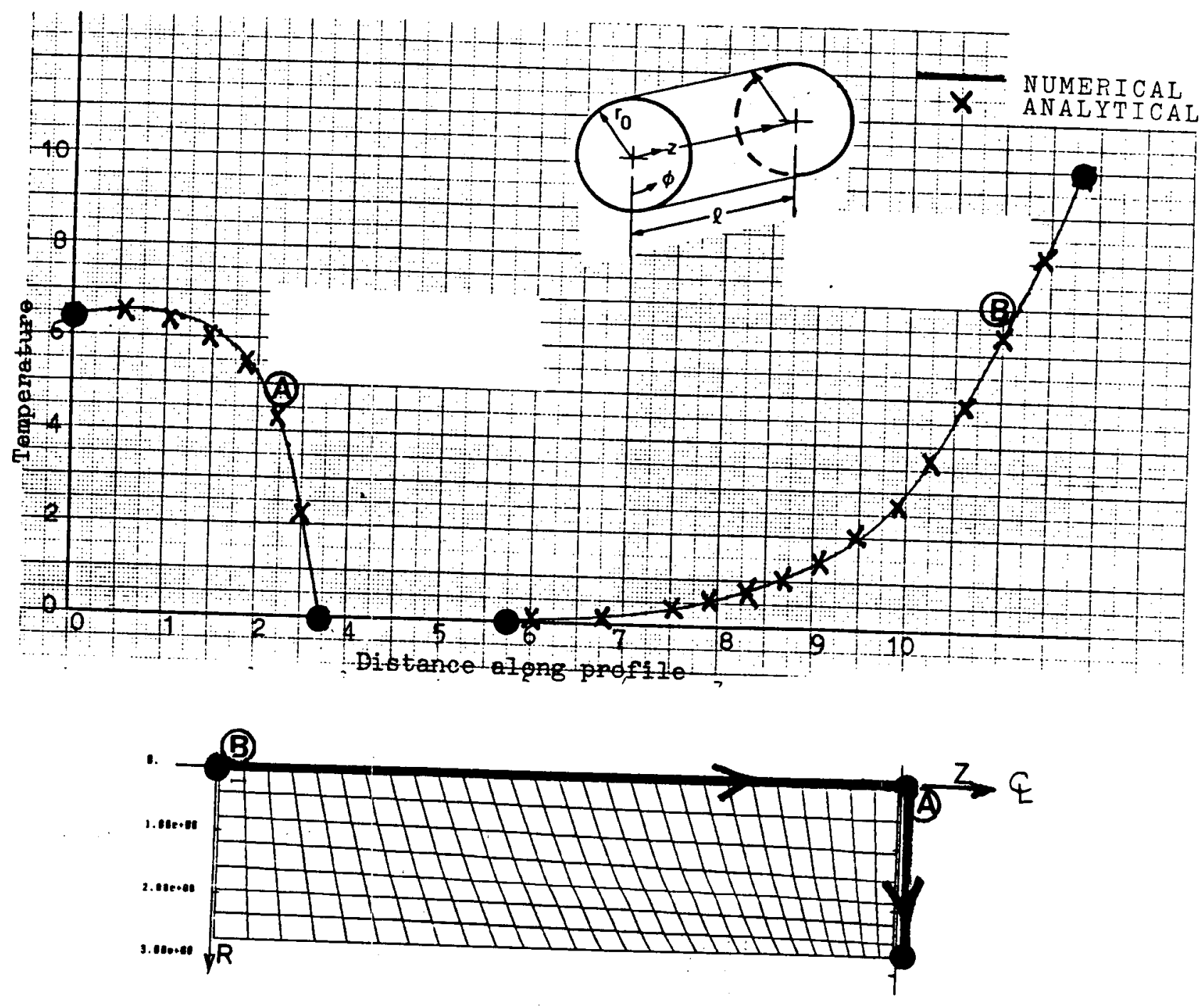

Figure 4-2 Analytical and numerical results for a steady-state heat flow in a finite cylinder with
two surface temperatures. 


\subsection{Example 2 - Slab with Nonlinear Material Properties}

Stewart and Wessling [8] analytically solved the following problem, which can be used for comparison in validating heat transfer computer codes. They found that several of the computer codes investigated did not correctly handle strong material nonlinearities.

The problem consists of a homogeneous, isotropic slab of finite thickness, 1, heated on the front face by a constant and uniform heat flux, $\ddot{q} "$, and insulated on the rear face (see Fig. 4-3 and Table 4-2).

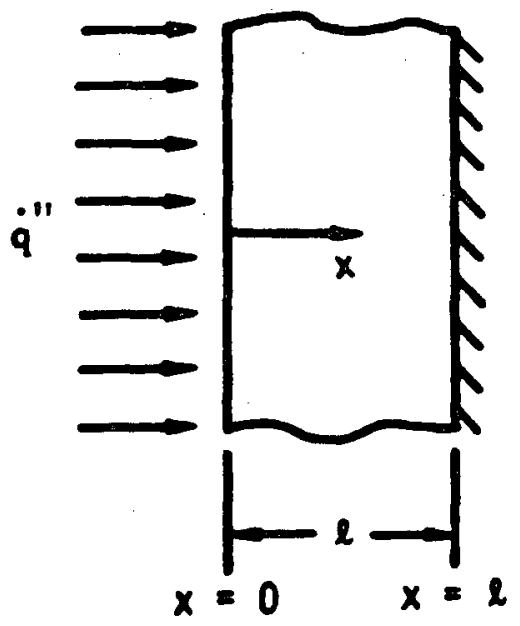

Figure 4-3 Heat conduction in homogeneous isotropic slab.

The appropriate form of the heat conduction equation is

$$
\frac{\partial}{\partial x}\left(k \frac{\partial T}{\partial x}\right)+\rho c \frac{\partial T}{\partial t}
$$

subject to the initial and boundary conditions

$$
\begin{aligned}
& \mathrm{T}(\mathrm{x}, 0)=\mathrm{T}_{0}, \\
& \frac{\partial \mathrm{T}}{\partial \mathrm{x}}(0, \mathrm{~T})=-\dot{\mathrm{q}} / \mathrm{k}, \\
& \frac{\partial \mathrm{T}}{\partial \mathrm{x}}(1, \mathrm{~T})=0 .
\end{aligned}
$$


This problem can be solved analytically for the special case $k=k(T), c=c(T)$, and $\rho=\rho(T)$ such that $\mathrm{k} / \rho \mathrm{c}=\alpha=$ constant. The solution is

$$
\frac{\beta T_{0} \theta^{2}}{2}+\theta=\frac{\dot{q} 1}{k_{0} T_{0}}\left(\frac{X^{2}}{2}-X+\frac{1}{3}+F o-\frac{2}{\pi^{2}} \sum_{n=1}^{\infty} \frac{1}{n^{2}} \cos n \pi X e-F_{0} n^{2} \pi^{2}\right),
$$

where

$$
\begin{aligned}
& \theta=\frac{T-T_{0}}{T_{0}}, \\
& X=\frac{x}{1}, \\
& F o=\frac{\alpha T}{1^{2}},
\end{aligned}
$$

Table 4-2 Input data for Example 2.

\section{Geometry and Material Properties}

$$
\begin{array}{rll}
1 & =0.03133 \mathrm{ft} \\
\rho & =500 \mathrm{lb} / \mathrm{ft}^{3} \\
\mathrm{k}(\mathrm{T}) & =\mathrm{k}_{0}\left[1+\beta\left(\mathrm{T}-\mathrm{T}_{0}\right)\right]=1.00[1+.005(\mathrm{~T}-530)] \mathrm{Btu} / \mathrm{hr} \mathrm{ft}^{\circ} \mathrm{R} \\
\mathrm{c}(\mathrm{T}) & =c_{0}\left[1+\beta\left(\mathrm{T}-\mathrm{T}_{0}\right)\right]=0.005[1+.005(\mathrm{~T}-530)] \mathrm{Btu} / \mathrm{b}_{\mathrm{m}}{ }^{\circ} \mathrm{R} \\
\mathrm{k}_{0} & =1 . \mathrm{Btu} / \mathrm{hr} \mathrm{ft}^{\circ} \mathrm{R} \\
\mathrm{c}_{0} & =0.05 \mathrm{Btu} / \mathrm{lb} \mathrm{b}^{\circ} \mathrm{R} \\
\beta & =0.0051 /{ }^{\circ} \mathrm{R}
\end{array}
$$

\section{Boundary and Initial Conditions}

$$
\begin{aligned}
& \mathrm{q}^{\prime \prime} \quad \doteq \quad 2.52 * 10^{6} \mathrm{Btu} / \mathrm{hr} \mathrm{ft}^{2} \\
& \mathrm{~T}_{0}=530^{\circ} \mathrm{R}
\end{aligned}
$$


The finite element mesh consisted of 40 elements in the $\mathrm{x}$-direction. By trial-and-error, it was found that fewer elements could not resolve the large temperature gradients existing in this program. Table 4-3 shows the analytical and numerical results for the temperature on the face at $x=0$ at various times.

Table 4-3 Comparison of results for Example 2.

\begin{tabular}{ccr}
\hline \multicolumn{3}{c}{ TEMPERATURE $\left[{ }^{\circ} \mathrm{R}\right]$ at $\mathrm{x}=0$} \\
\hline TIME hr] & ANALYTICAL & TOPAZ \\
\hline $1 \times 10^{-6}$ & 847.19 & 845.44 \\
$1 \times 10^{-5}$ & 1201.41 & 1200.24 \\
$1 \times 10^{-4}$ & 1851.45 & 1850.43 \\
\hline
\end{tabular}

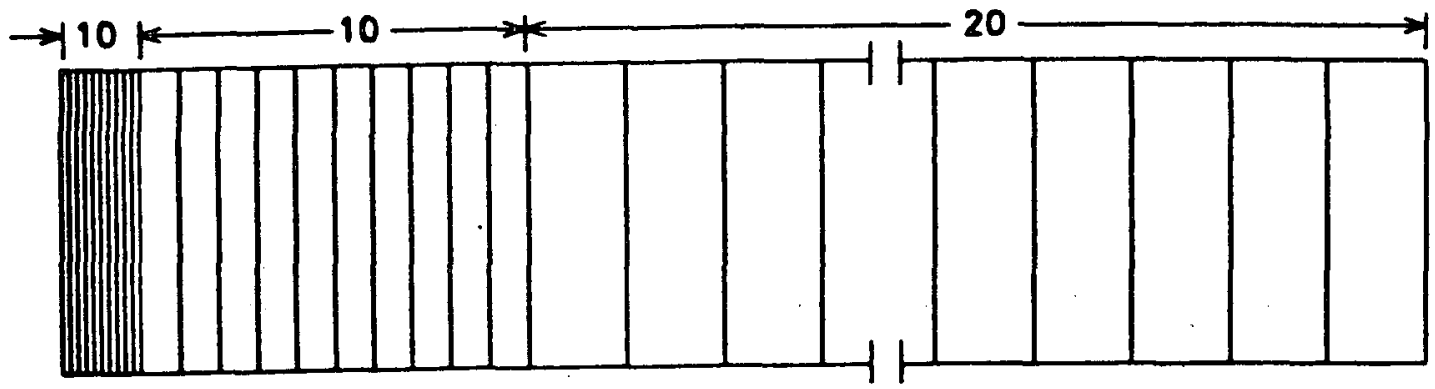




\subsection{Example 3 - Cylinder with Temperature + Convection Boundary Conditions}

Carslaw and Jaeger [9] provide a solution for steady heat flow in a solid cylinder with the temperature on the bottom at at fixed temperature and the side and the top subject to convective cooling. The material thermal properties are held constant. (See Fig. 4-4 and Table 4-4) This twodimensional problem has the exact analytical solution (see Fig. 4-5):

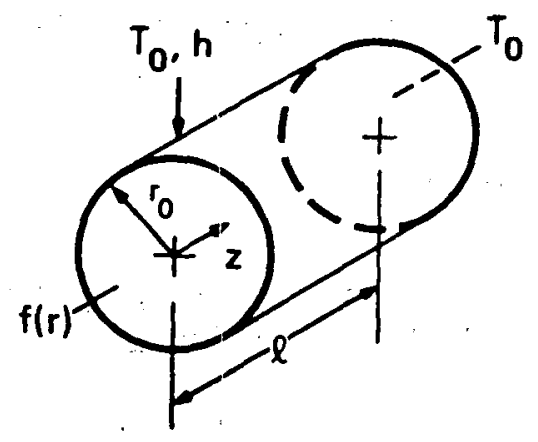

Finite cylinder with:

$$
\begin{aligned}
& \mathrm{T}=\mathrm{f}(\mathrm{r}), \mathrm{z}=0,0<\mathrm{r}<\mathrm{r}_{0} . \\
& \mathrm{T}=\mathrm{T}_{0}, \mathrm{z}=1,0<\mathrm{r}<\mathrm{r}_{0} .
\end{aligned}
$$

Convection boundary at $r=r_{0}, 0<z<1$, with $h, T_{0}$.

Figure 4-4 Finite solid cylinder with convection.

$$
\begin{aligned}
& \mathrm{L}=\mathrm{I} / \mathrm{r} 0, \mathrm{Bi}=\mathrm{hr} / \mathrm{k}, \lambda_{\mathrm{n}} \mathrm{f}_{0}^{\prime}\left(\lambda_{\mathrm{n}}\right)+\mathrm{Bi} \mathrm{J}_{0}\left(\lambda_{n}\right)=0, \lambda_{\mathrm{n}}>0 \\
& \frac{T-T_{0}}{T_{1}-T_{0}}=2 B i \sum_{n=1}^{\infty} \frac{J_{0}\left(R \lambda_{n}\right) \sinh \left([1-z] L \lambda_{n}\right)}{\left(B i^{2}+\lambda_{n}^{2}\right) J_{0}\left(\lambda_{n}\right) \sinh \left(L \lambda_{n}\right)}
\end{aligned}
$$

Table 4-4 Input data for Example 3.

\section{Geometry and Material Properties}

$\begin{array}{ll}1 & =10.87313 \mathrm{~m} \\ \mathrm{r}_{0} & =\quad 2.71828 \mathrm{~m} \\ \mathrm{k} & =3 \mathrm{~W} / \mathrm{m}^{\circ} \mathrm{C} \text {, thermal conductivity }\end{array}$

\section{Boundary Conditions}

h $=1.10364 \mathrm{~W} / \mathrm{m}^{2}{ }^{\circ} \mathrm{C}$ heat transfer coefficient applied over 21

$\mathrm{T}_{0}=0^{\circ} \mathrm{C}$, environment temperature

$\mathrm{T}_{1}=10^{\circ} \mathrm{C}$, environment temperature $=\mathrm{f}(\mathrm{r})$ 

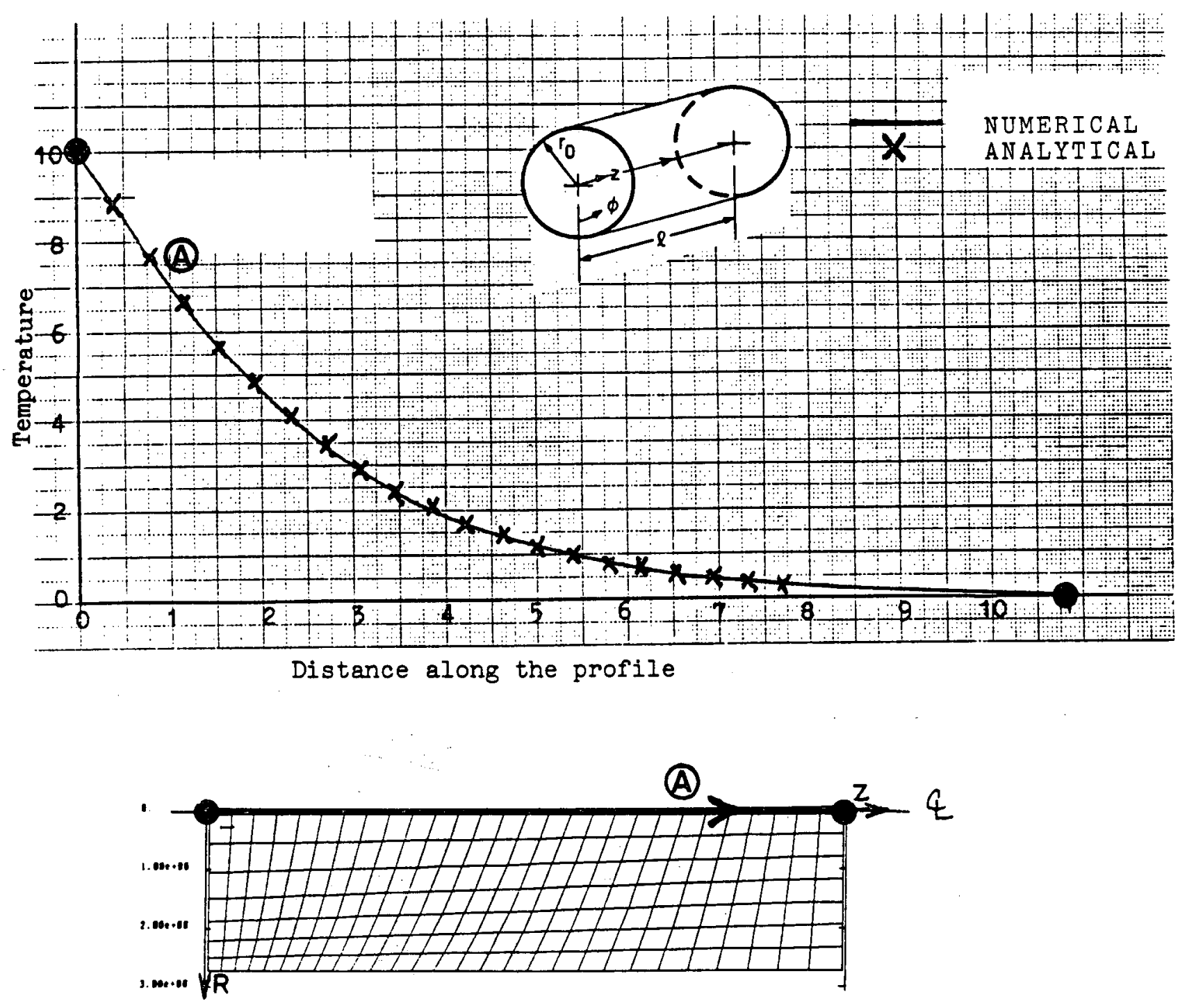

Figure 4-5 Analytical and numerical results of temperature plus convection boundary conditions in a cylinder. 


\subsection{Example 4 - One-Dimensional Cylinder with Heat-Generating Core}

Sandia National Laboratory was contracted to study the performance of general purpose thermal analysis codes used for evaluating the response of nuclear fuel shipping casks to thermal loads. As part of this work, they developed a standard set of thermal models consistent with many shipping cask designs [10]. Model 1 of this standard set consists of a composite two-region cylinder of length $\mathrm{L}$, with a central region that generates heat (Fig. 4-6). The central core (region 1 with $\mathrm{r} \leqq \mathrm{r}_{1}$ ) generates heat at $11090 \mathrm{~W} / \mathrm{m}^{3}$, a value representative of spent fuel shipments, while the external surface of region $2\left(r_{1}<r \leqq r_{2}\right)$ is subjected to a convective boundary condition equal to 5.67 $\mathrm{W} / \mathrm{m}^{2}-\mathrm{K}$, simulating natural convection in room temperature air. With all material properties held constant (Table 4-5), this one-dimensional steady-state problem has an exact analytical solution (Fig. 4-7) [10].

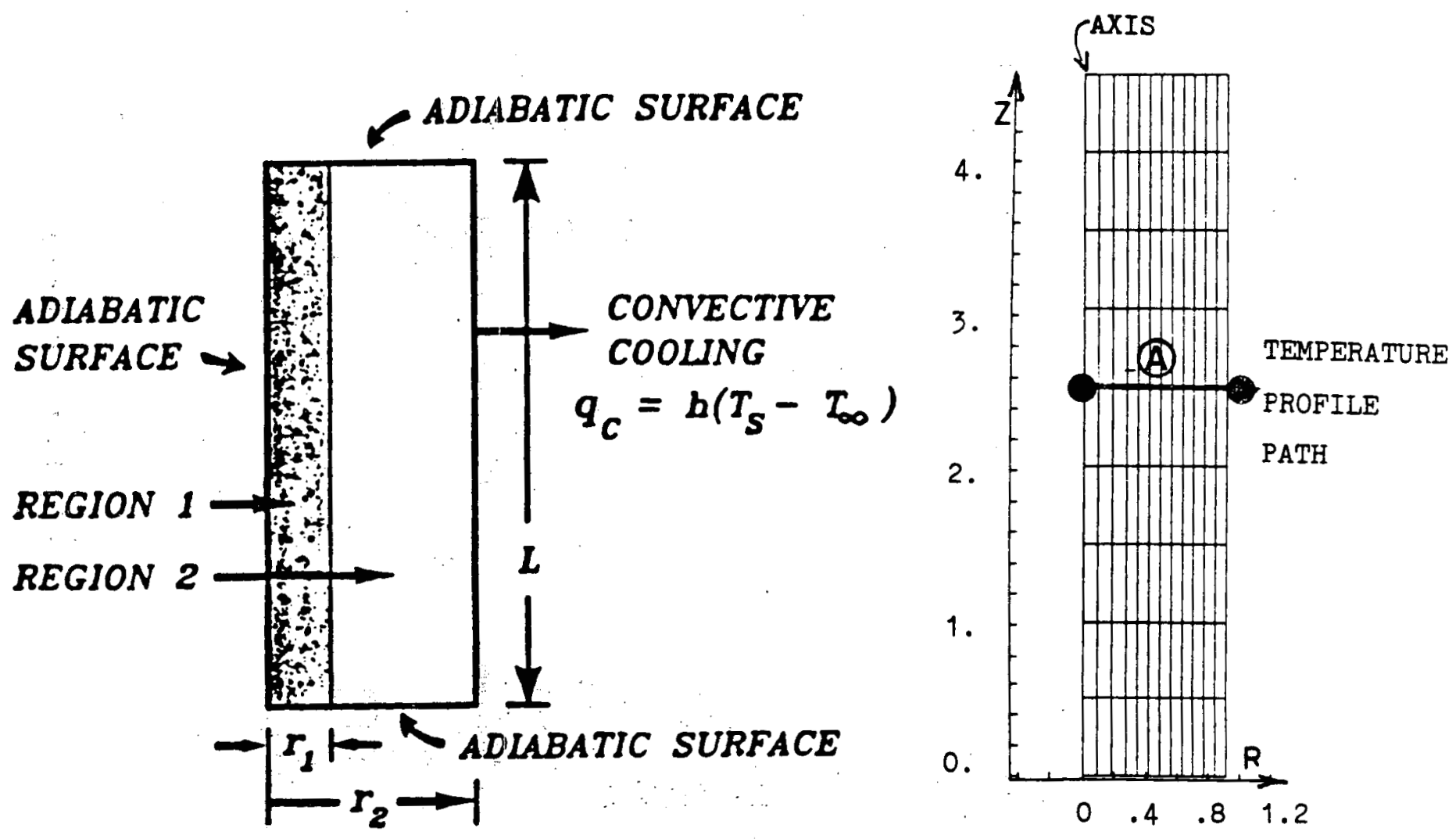

Figure 4-6 SNL Model 1 geometry and LLNL finite element mesh. 
The exact solution is:

$$
\begin{aligned}
& 0 \leq r \leq r_{1} T(r)=T_{\infty}+Q r_{1}^{2}\left[\frac{1}{2 r_{2} h}-\frac{\ln \left(r_{1} / r_{2}\right)}{2 k_{2}}+\frac{1}{4 k_{1}}\left(1-\frac{r^{2}}{2}\right)\right] \\
& r_{1} \leq r \leq r_{2} T(r)=T_{\infty}+Q r_{1}{ }^{2}\left[\frac{1}{2 r_{w} h}-\frac{\ln \left(r_{1} / r_{2}\right)}{2 k_{2}}\right] .
\end{aligned}
$$

Table 4-5 Input data for Example 4.

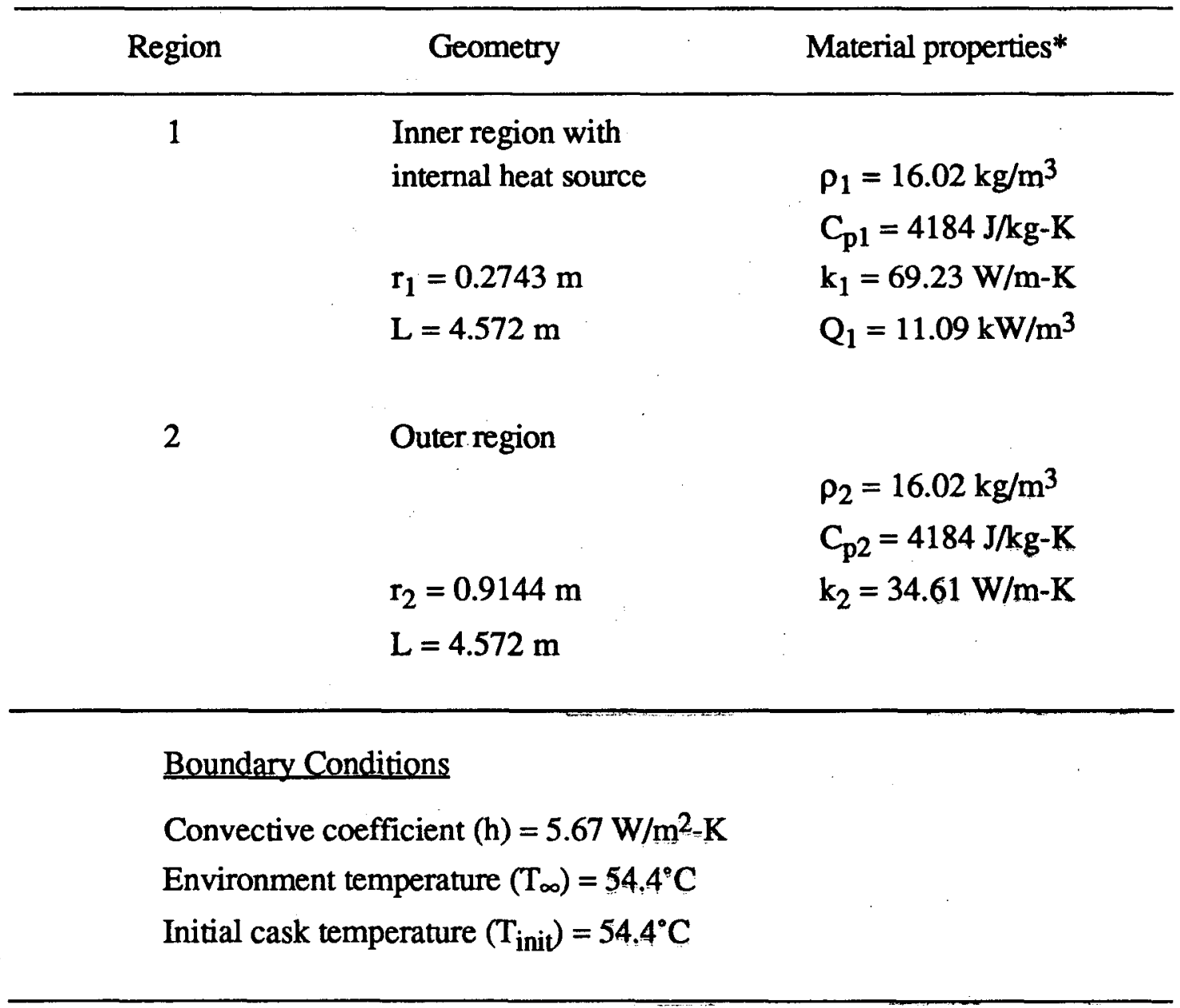

* These material properties not representative of real materials.

The second figure set shows the analytical and numerical results. 


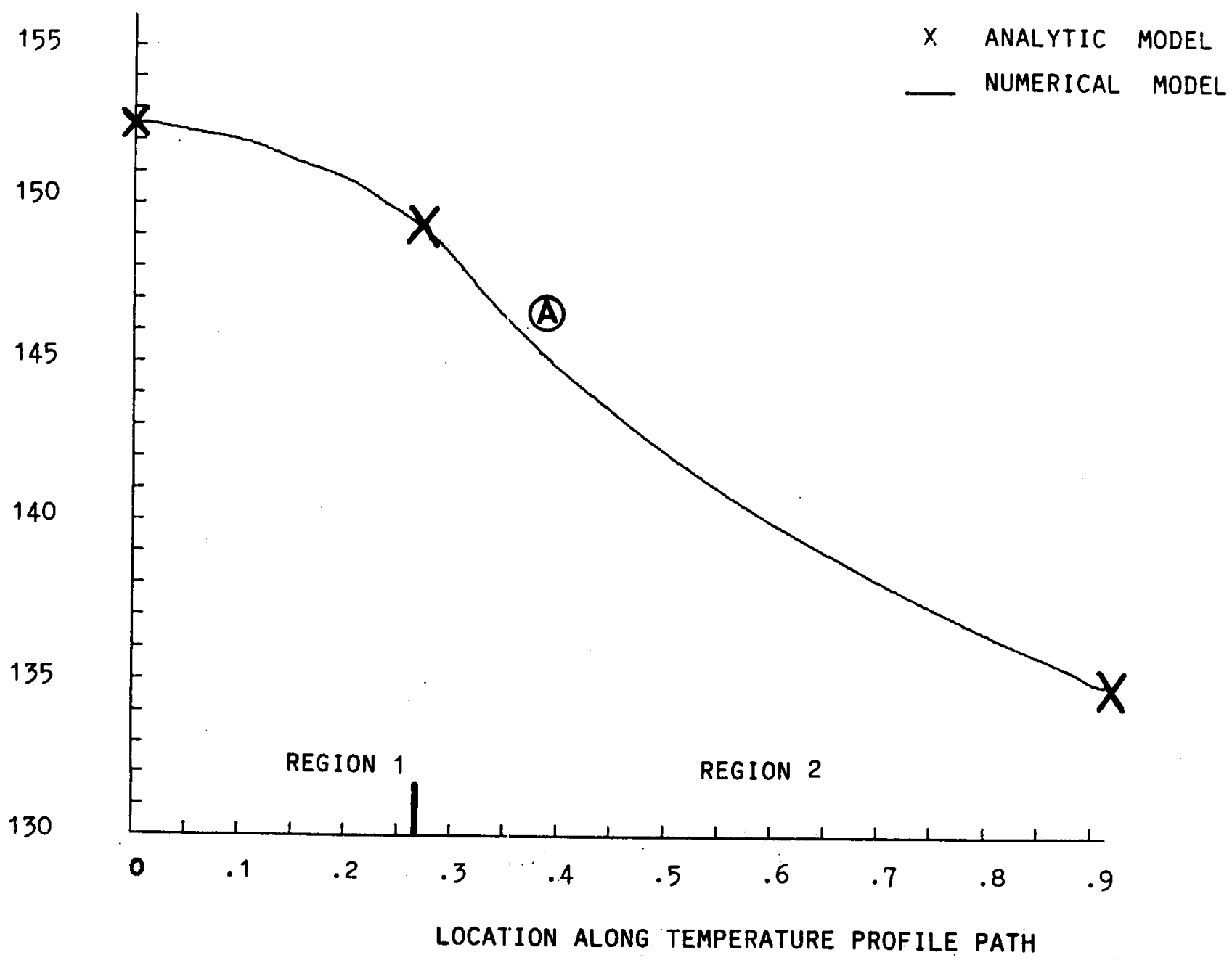

Figure 4-7 Analytical and numerical results for one dimensional cylinder with internal heating. 


\subsection{Example 5 - Finite Rod with Band Heating}

Carslaw and Jaeger [7] provide a solution for steady-state heat flow in a hollow cylinder with a flux boundary condition heat source on the middle of the rod side surface and convection boundary conditions over the entire side surface. The material thermal properties are held constant (see Fig. 48 and Table 4-6). This two-dimensional problem has the exact analytical solution (Fig. 4-9):

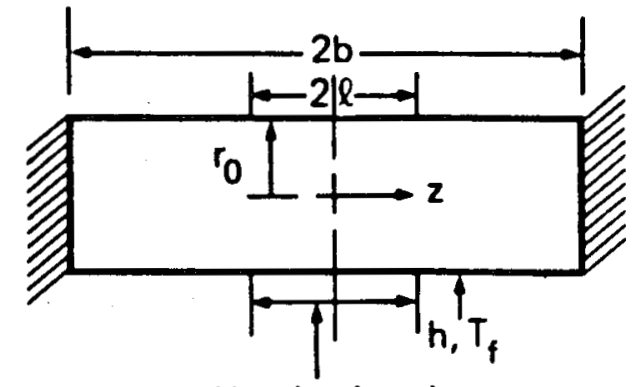

Heating band
Finite rod with band heating,

$\mathrm{q}_{\mathrm{z}}=0, \mathrm{z}= \pm \mathrm{b}$..

Convection boundary at $r=r_{0}$, $-\mathrm{b}<\mathrm{z}<+\mathrm{b}$.

Surface heating $\left(\mathrm{q}_{\mathrm{s}}\right)$ at $\mathrm{r}=\mathrm{r}_{0}$,

$-1<\mathrm{z}<+1$.

Figure 4-8 Finite rod with heating band.

$$
\begin{aligned}
\frac{\left(T-T_{f}\right)}{q_{s} r_{0} / k} & =\frac{L}{B i}+2 \sum_{n=1}^{\infty} \frac{\sin \left(\lambda_{n} L\right) I_{0}\left(\lambda_{n} \rho R\right) \cos \left(\lambda_{n} z\right)}{\lambda_{n}\left[B i I_{0}\left(\lambda_{n} \rho\right)+\left(\lambda_{n} \rho\right) I_{1}\left(\lambda_{n} \rho\right)\right]} \\
\lambda_{n} & =n \pi, B i=h r_{0} / k, L=1 / b, Z=z / b \\
R & =r / r_{0}, \rho=r_{0} / b
\end{aligned}
$$

Table 4-6 Input data for Example 5.

Geometry and Material Properties

$\begin{array}{lll}\mathrm{l} & = & 5.43657 \mathrm{~m} \\ \mathrm{r}_{\mathrm{O}} & = & 2.71828 \mathrm{~m} \\ \mathrm{k} & = & 3 \mathrm{~W} / \mathrm{m}-\mathrm{K}, \text { thermal conductivity }\end{array}$

Boundary Conditions

$\begin{array}{lll}\mathrm{b} & = & 2.71828 \mathrm{~m} \\ \mathrm{q}_{\mathrm{s}} & = & 4.41555 \mathrm{~W} / \mathrm{m}^{2}, \text { heat flux applied over } 2 \mathrm{~b} \\ \mathrm{~h} & = & 1.10364 \mathrm{~m}, \text { heat transfer coefficient applied over } 21 \\ \mathrm{~T}_{\mathrm{f}} & = & 10^{\circ} \mathrm{C}, \text { environment temperature }\end{array}$



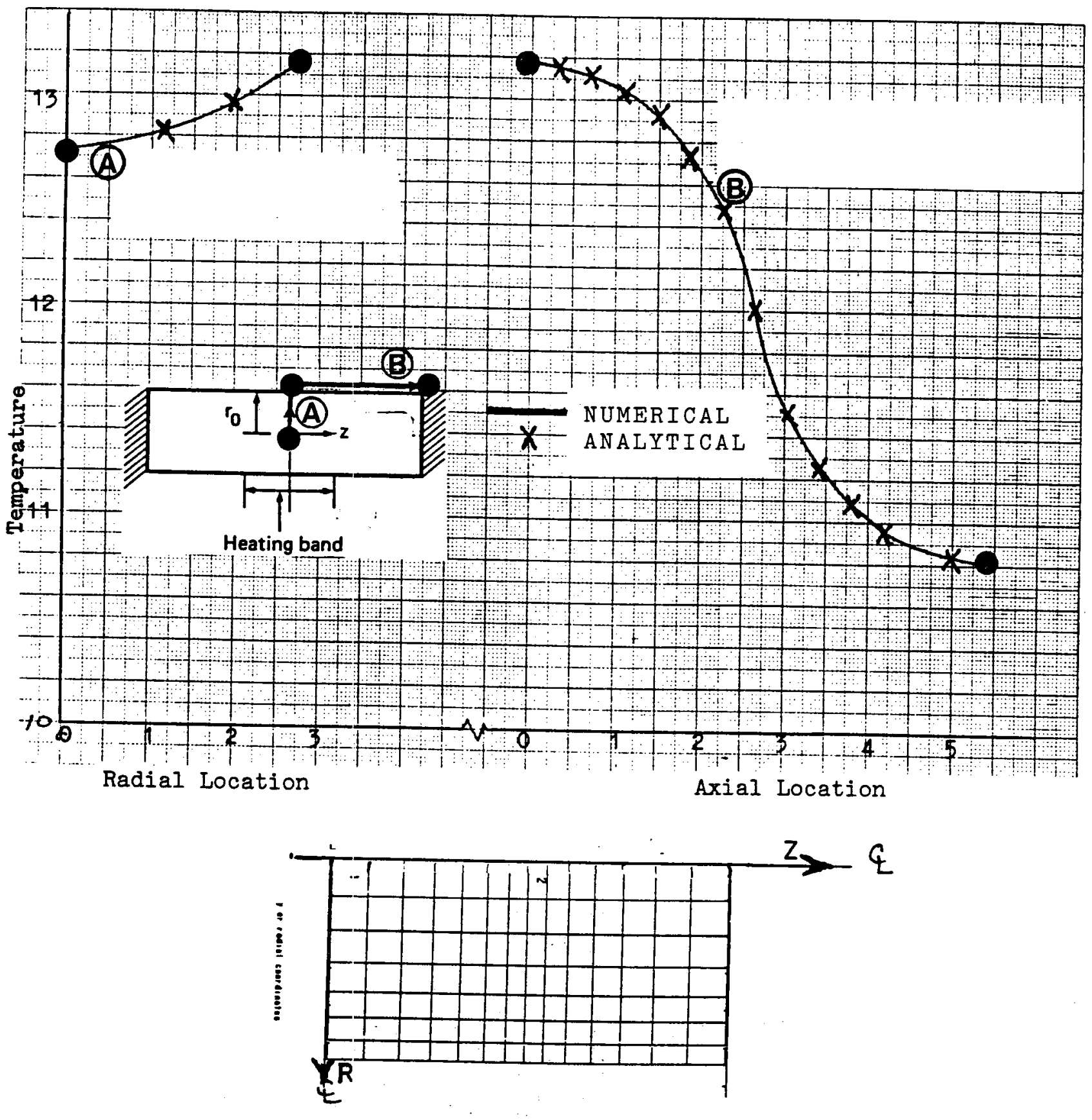

Figure 4-9 Analytical and numerical results for steady-state heat flow in a finite rod with band heating. 


\subsection{Example 6 - Finite Cylinder with Strip Heating and Cooling}

Carslaw and Jaeger [7] provide a solution for steady-state heat flow in a solid cylinder with a heating flux boundary condition source at one end of the cylinder's side surface and an equivalent cooling flux boundary condition at the other end (Fig. 4-10). The material thermal properties are held constant (Table 4-7). This two-dimensional problem has the exact analytical solution (Fig. 4-11):

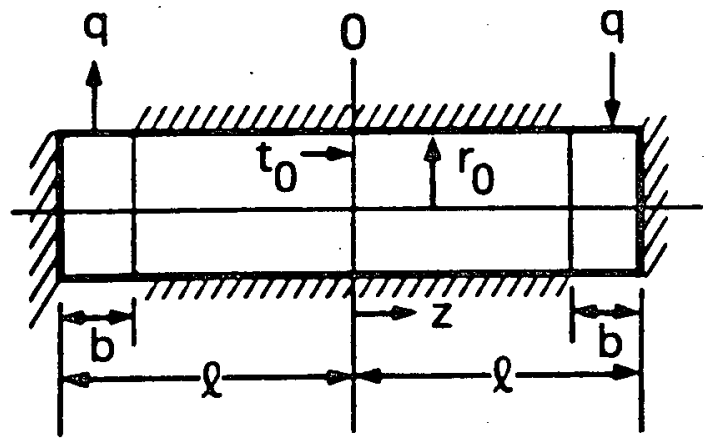

$$
\begin{aligned}
& \mathrm{q}_{\mathrm{r}}=-\mathrm{q}_{1}, \mathrm{r}=\mathrm{r}_{0}, 1>\mathrm{x}>1-\mathrm{b} . \\
& \mathrm{q}_{\mathrm{r}}=0, \mathrm{r}=\mathrm{r}_{0}, 1-\mathrm{v}>\mathrm{z}>-1+\mathrm{b} . \\
& \mathrm{q}_{\mathrm{r}}=+\mathrm{q}_{1}, \mathrm{r}=\mathrm{r}_{0},-1+\mathrm{b}>\mathrm{z}>-1 . \\
& \mathrm{q}_{\mathrm{z}}=0, \mathrm{z}= \pm 1, \mathrm{r}=\mathrm{r}_{0} . \\
& \mathrm{T}=\mathrm{T}_{0}, \mathrm{z}=0,0<\mathrm{r}<\mathrm{r}_{0} .
\end{aligned}
$$

Figare 4-10 Finite cylinder with strip heating and cooling.

$$
\frac{\left(T-T_{0}\right) k}{q_{1} 1}=\frac{8}{\pi^{2}} \sum_{n=0}^{\infty} \frac{(-1)^{n} I_{0}(m \pi R)}{m^{2} I_{1}\left(m \pi R_{0}\right)} \sin (m \pi b / 1) \sin (m \pi Z)
$$

where

$$
m=2 n+1, R=r / 21, Z=z / 21, B=b / 21 .
$$

Table 4-7 Input data for Example 6.

Geometry and Material Properties

$\begin{array}{lll}1 & = & 5.43657 \mathrm{~m} \\ \mathrm{r}_{\mathrm{o}} & = & 2.71828 \mathrm{~m}\end{array}$

Boundary Conditions

$\begin{array}{ll}\mathrm{b} & =1.35914 \mathrm{~m} \\ \mathrm{q}_{\mathrm{s}} & =5.5182 \mathrm{~W} / \mathrm{m}^{2}, \text { heat flux applied over } 2 \mathrm{~b} \\ \mathrm{~T}_{0} & =10^{\circ} \mathrm{C}, \text { center-plane temperature }\end{array}$



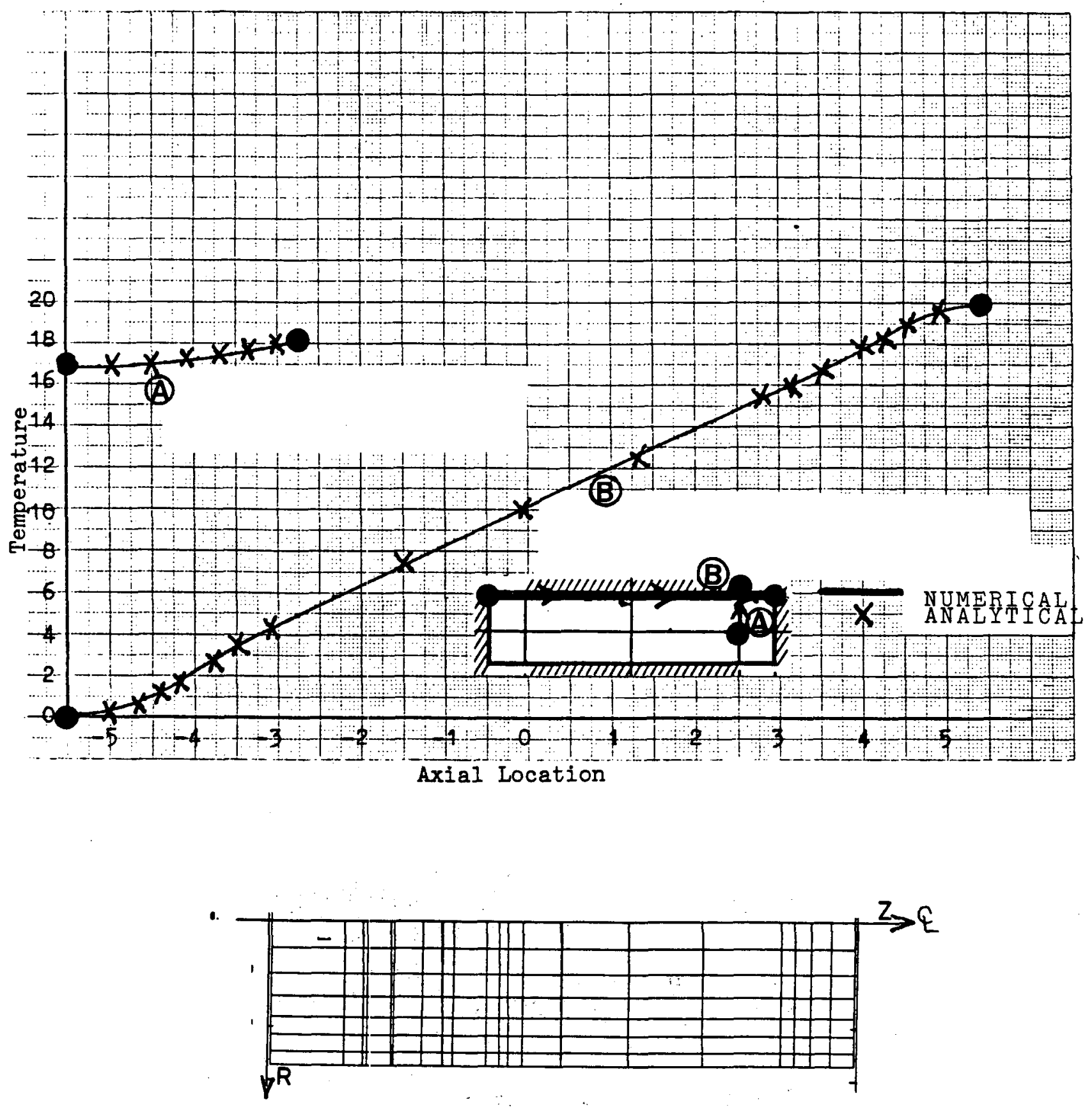

Figure 4-11 Analytical and numerical results for steady-state heat flow in a finite cylinder with strip heating and cooling. 


\subsection{Example 7 - Finite Hollow Cylinder with Inside Band Heating}

Carson and Jaeger [7] provide a solution for steady-state heat flow in a solid cylinder with a flux boundary condition heat source on the middle of the inside surface of the cylinder and fixed temperature boundary conditions over the remaining surface (Fig. 4-12). The material thermal properties are held constant (Table 4-7). This two-dimensional problem has the exact analytical solution (Fig. 4-13):

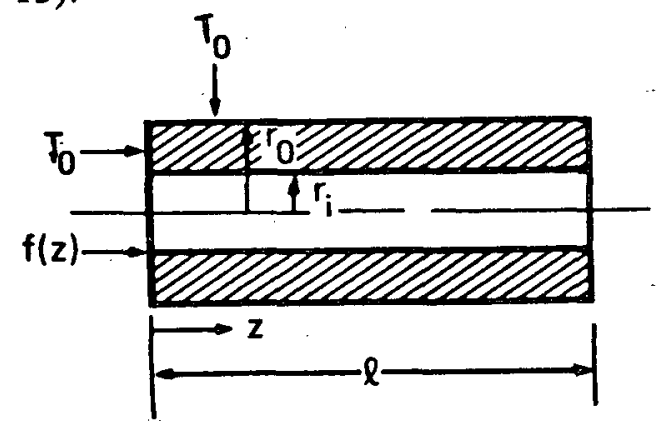

Finite hollow cylinder with:

Figure 4-12 Finite hollow cylinder with inside bond heating.

$$
\begin{aligned}
& F_{0}=I_{0}(n \pi R) K_{0}\left(n \pi R_{0}\right)-K_{0}(n \pi R) I_{0}\left(n \pi R_{0}\right), \\
& F_{1}=I_{1}\left(n \pi R_{i}\right) K_{0}\left(n \pi R_{0}\right)-K_{1}\left(n \pi R_{i}\right) I_{0}\left(n \pi R_{0}\right),
\end{aligned}
$$

where

$$
\begin{aligned}
& R=r / l \text { and } W=w / l \\
& \frac{\left(T-T_{0}\right) k}{q_{1} l}=\sum_{n=1}^{\infty} \frac{F_{0}}{n^{2} F_{1}} \cos (n \pi W) \sin (n \pi Z), n=1,3,5, \ldots
\end{aligned}
$$

\begin{tabular}{|c|c|c|}
\hline 1 & $=$ & $10.87313 \mathrm{~m}$ \\
\hline$r_{0}$ & $=$ & $2.71828 \mathrm{~m}$ \\
\hline$r_{i}$ & 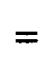 & $1 \mathrm{~m}$ \\
\hline 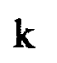 & $=$ & $3 \mathrm{~W} / \mathrm{m}-\mathrm{K}$, thermal conductivity \\
\hline
\end{tabular}

Table 4-8 Input data for Example 7.

Geometry and Material Properties

$\underline{\text { Boundary Conditions }}$

$$
\begin{array}{lll}
\mathrm{w} & =2.71828 \mathrm{~m} \\
\mathrm{q}_{1} & =55.182 \mathrm{~W} / \mathrm{m}^{2}, \text { heat flux applied over } \mathrm{w} \text { on } \mathrm{r}_{\mathbf{i}} \\
\mathrm{T}_{0} & =0^{\circ} \mathrm{C}, \text { surface temperature }
\end{array}
$$



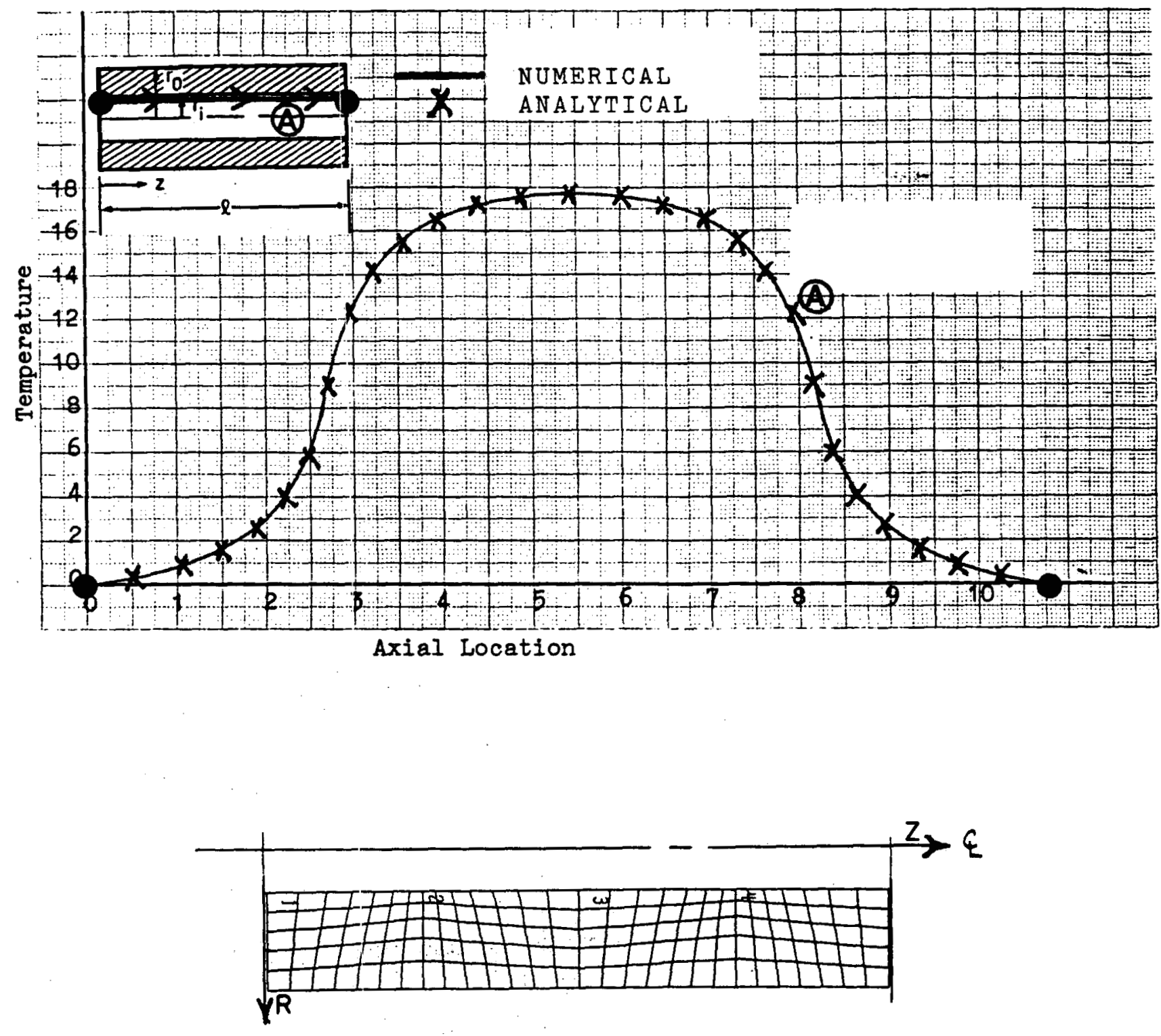

Figure 4-13 Analytical and numerical results for steady-state heat flow in a finite hollow cylinder with inside band heating. 


\subsection{Example 8 - Regulation Case-Normal Hot Day with Maximum Decay Heat/Solar Heat}

Along with Example 9, this case is included to benchmark the PC-based version of TOPAZ with the validated version on the LLNL CRAY mainframe machines. The geometry for this example is similar to some spent fuel shipping cask designs (Fig. 4-14).

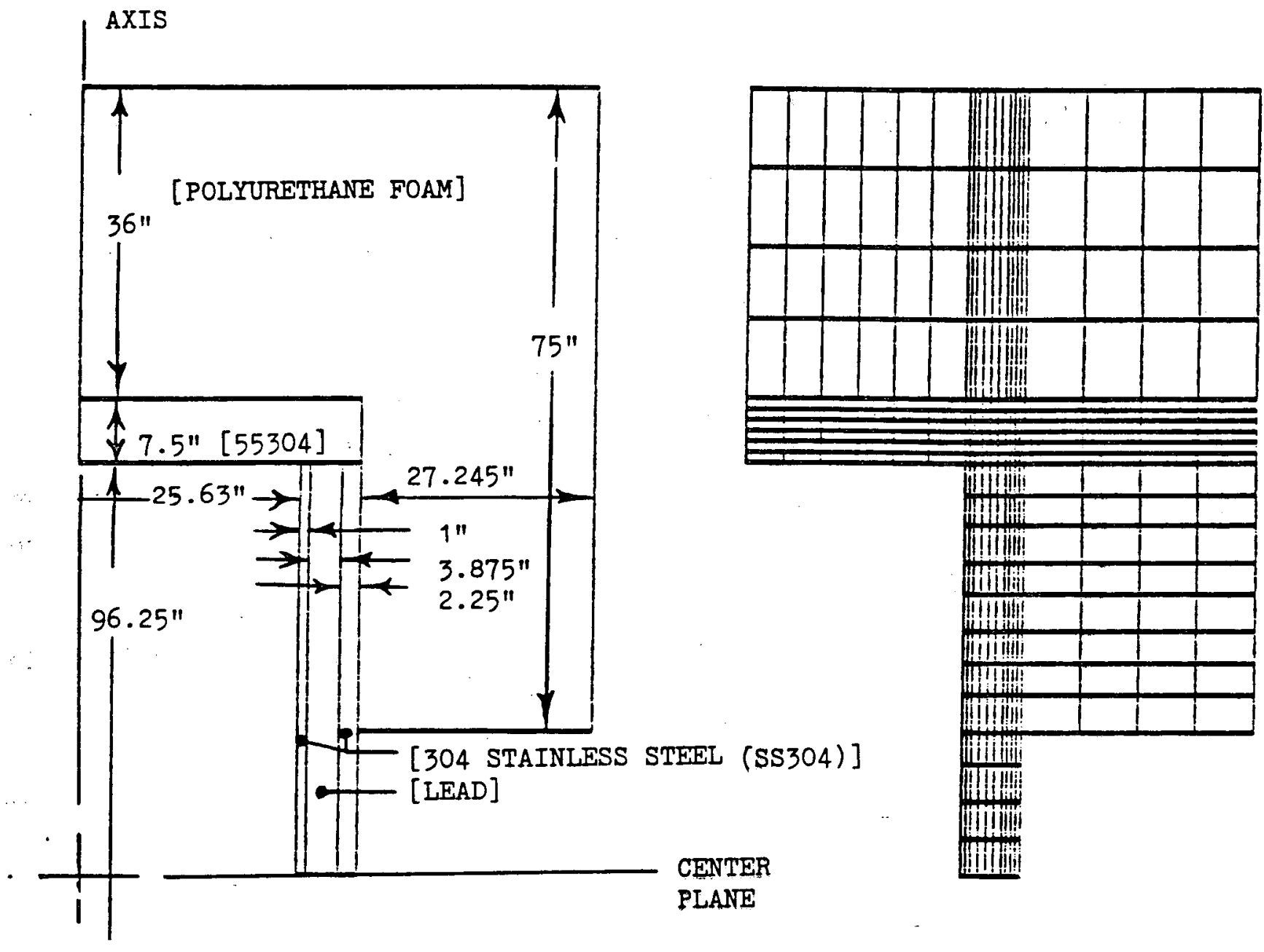

Figure 4-14 Geometry and finite element mesh for regulation case. Normal hot with maximum heat. 
The thermal load is based on the regulation-defined case assuming a $100^{\circ} \mathrm{F}$ ambient temperature with natural convection cooling and $95 \mathrm{Btu} / \mathrm{hr}-\mathrm{ft}^{2}$ solar heating over the entire external surface. The decay heat, $500 \mathrm{Btu} / \mathrm{min}$, is spread uniformly in terms of an heat flux boundary condition on the surface of the cask cavity. The temperature-dependent heat transfer coefficients for the cylindrical and end surfaces are given by

$$
\begin{aligned}
& \mathrm{h}_{\mathrm{cyl}}=2.118 \times 10^{-5}\left(\mathrm{~T}-\mathrm{T}_{\mathrm{amb}}\right)^{1 / 3} \mathrm{Btu} / \mathrm{min}^{-i n^{2}-{ }^{\circ} \mathrm{F}} \\
& \mathrm{h}_{\mathrm{end}}=2.095 \times 10^{-5}\left(\mathrm{~T} \cdot \mathrm{T}_{\mathrm{amb}}\right)^{1 / 3} \mathrm{Btu} / \mathrm{min}^{-\mathrm{in}^{2}-{ }^{\circ} \mathrm{F}}
\end{aligned}
$$

For stainless steel 304 , the density is $0.28414 \mathrm{lbm} / \mathrm{in}^{3}$. The specific heat capacity $\left(\mathrm{Btu} / \mathrm{bm}-{ }^{\circ} \mathrm{F}\right)$ and the thermal conductivity (Btu/min-in- ${ }^{\circ} \mathrm{F}$ ) vs temperature $\left({ }^{\circ} \mathrm{F}\right)$ are given in Table 4-9.

Table 4-9 Stainless steel specific heat capacity and thermal conductivity.

\begin{tabular}{rrrrrrrrr}
\hline $\mathrm{T}:$ & -58. & 68 & 212. & 392 & 572 & 752. & 1112. & 1472. \\
$\mathrm{Cp}:$ & .01125 & .0114 & .012083 & .012083 & .013056 & .013889 & .015278 & .018056 \\
$\mathrm{k}:$ & .12 & .123 & .12375 & .1275 & .13125 & .135 & .1425 & .15 \\
\hline
\end{tabular}

For lead, the density is $0.411 \mathrm{lbm} / \mathrm{in}^{3}$. The melt temperature is $620^{\circ} \mathrm{F}$, and the heat of fusion is $10.26 \mathrm{Btu} / \mathrm{lbm}$. The specific heat capacity $\left(\mathrm{Btu} / \mathrm{lbm}-{ }^{\circ} \mathrm{F}\right)$ and thermal conductivity $\left(\mathrm{Btu} / \mathrm{min}-\mathrm{in}-{ }^{\circ} \mathrm{F}\right)$ vs temperature $\left({ }^{\circ} \mathrm{F}\right)$ are given in Table 4-10.

Table 4-10 Lead specific heat capacity and thermal conductivity.

\begin{tabular}{rrrrrrrrr}
\hline $\mathrm{T}:$ & -58. & 68 & 212 & 392 & 572 & 630 & 717. & 1276. \\
$\mathrm{Cp}:$ & .028888 & .0280 & .0268 & .025278 & .023889 & .016806 & .013472 & .012028 \\
$\mathrm{k}:$ & .03 & .0307 & .0315 & .032598 & .033695 & .034 & .033914 & .033653 \\
\hline
\end{tabular}

For polyurethane foam, the density is $0.01157 \mathrm{lbm} / \mathrm{in}^{3}$. The specific heat capacity $\left(\mathrm{Btu} / \mathrm{lbm}-{ }^{\circ} \mathrm{F}\right)$ and thermal conductivity (Btu/min-in- $\left.{ }^{\circ} \mathrm{F}\right)$ vs temperature $\left({ }^{\circ} \mathrm{F}\right)$ are given in Table 4-11. 
Table 4-11 Polyurethane form specific heat capacity and thermal conductivity.

\begin{tabular}{rccc}
\hline $\mathrm{T}:$ & -58. & 68. & 1300. \\
$\mathrm{Cp}:$ & .000278 & .000278 & .000278 \\
$\mathrm{k}:$ & .3 & .3 & .3 \\
\hline
\end{tabular}

Figure 4-15 shows a comparison between the CRAY version prediction and the PC version prediction of the temperature profiles along the cask axis and the cask center plane. 


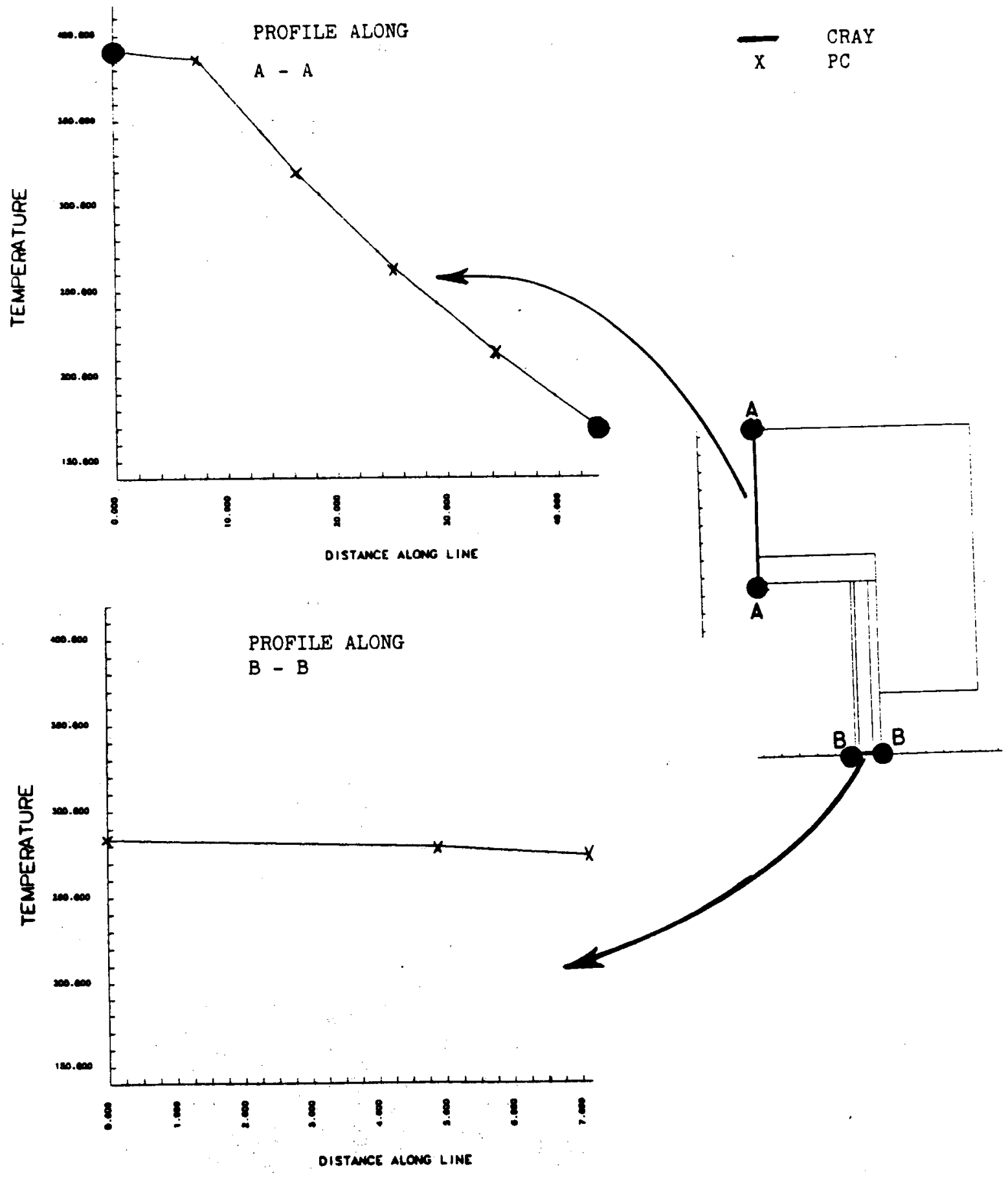

Figure 4-15 Comparison between CRAY version of TOPAZ and the PC version of TOPAZ for Example 8. 


\subsection{Example 9 - Regulation Case-Cold Soak with Maximum Decay Heat/No Solar Heat}

This case is also included to benchmark the PC-based version of TOPAZ with the welldocumented version on the LLNL CRAY mainframe machines. The geometry for this example is the same as Example 8. The thermal load is based on the regulation-defined case assuming a $-40^{\circ} \mathrm{F}$ ambient temperature with natural convection cooling over the entire external surface. The remaining input data is the same as Example 8.

Figure 4-16 shows a comparison between the CRAY version prediction and the PC version prediction of the temperature profiles along the cask axis and the cask center plane. 

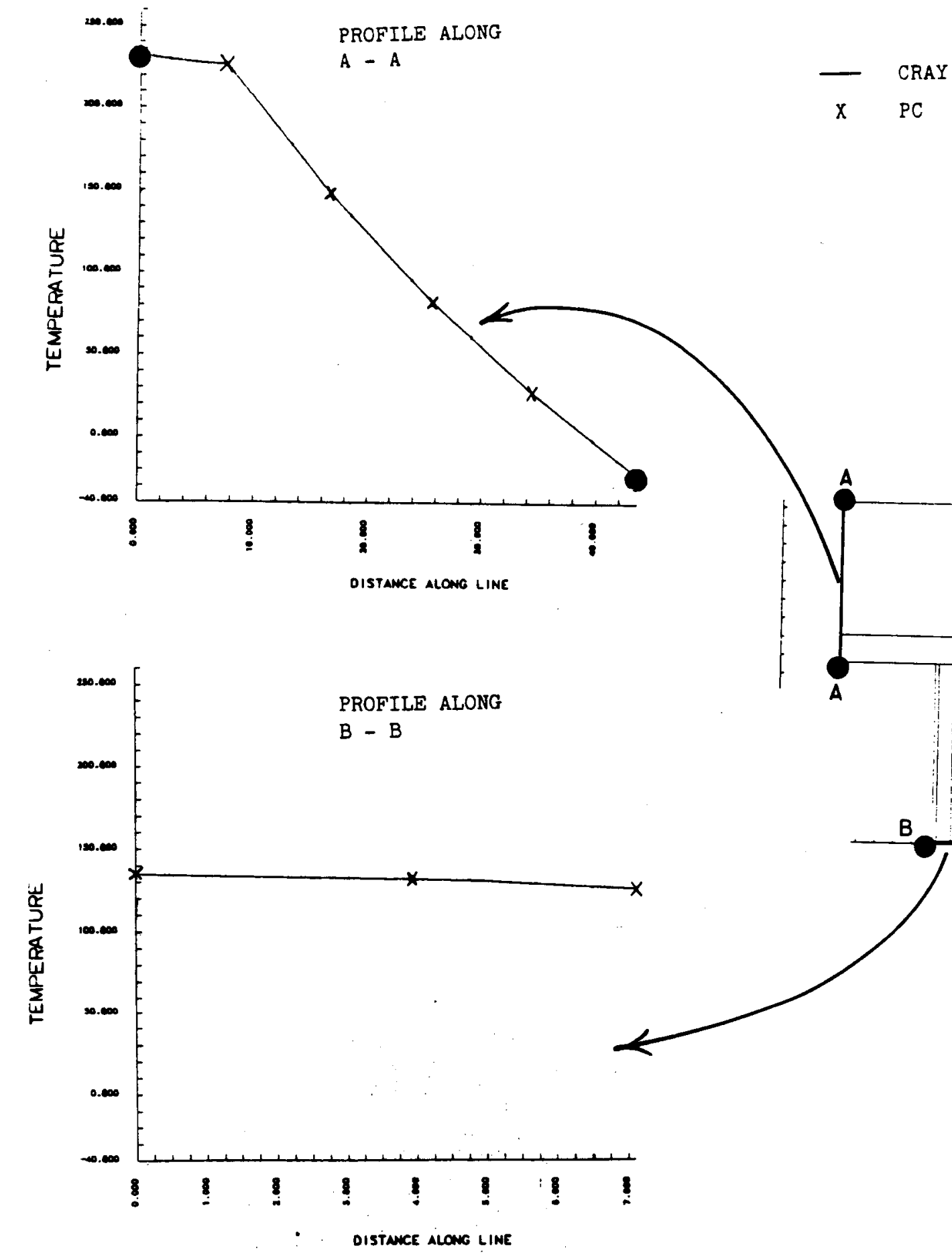


\subsection{REFERENCES}

1. O. C. Zienkiewicz, The Finite Element Method, McGraw-Hill Book Company (UK) Limited, London, 3rd ed. Appendix 3 (1977).

2. T. J. R. Hughes, "Unconditionally Stable Algorithms for Nonlinear Heat Conduction," Computer Methods in Applied Mechanics and Engineering, Vol. 10, pp 135-139 (1977).

3. H. C. Hottel and A. F. Sarofim, Radiative Transfer, McGraw Hill, New York (1967).

4. R. Siegel and J. R. Howell, Thermal Radiation Heat Transfer, McGraw-Hill, New York (1981).

5. N. E. Gibbs, W. G. Poole, and P. K. Stockmeyer, "An Algorithm for Reducing the Bandwidth and Profile of a Sparse Matrix," SIAM Journal of Numerical Analysis, Vol. 13, No. 2, pp. 236-250 (April 1976).

6. W. D. Ralph III and K. J. Bathe, "An Efficient Algorithm for Analysis of Nonlinear Heat Transfer with Phase Change," Int. J. Num. Meth. Eng, Vol. 18, pp. 119-134 (1982).

7. H. S. Carslaw and J. C. Jaeger, Conduction of Heat in Solids, Oxford University Press, London (1980).

8. R. E. D. Stewart and F. C. Wessling, Jr., "On Heat Conduction in Solids," Sandia National Laboratories, Rept. SC-RR-70-334 (1970).

9. Carslaw and Jaeger, Conduction Heating in Solids, Oxford at the Clarenden Press, Copyright 1959, second edition 1984, pg. 192.

10. L. C. Sanchez, ed., Performance Testing of Thermal Analysis Codes for Nuclear Fuel Casks, Sandia Report SAND84-1854, Sandia National Laboratory, Albuquerque, NM (1987). 